\title{
El futuro de la evolución \\ 姜 Y de la especie humana \\ ¿hacia una era \\ post/trans-humanista?
}

\section{Carlos Beorlegui Universidad de Deusto}

Resumen: Algunos estudios científicicos consideran que estamos al borde de superar la frontera de lo humano para adentrarnos en una era nueva llamada post-humana o trans-humana. El presente trabajo propone una cierta clarificación dentro de estas propuestas de repensar lo humano, así como una serie de reflexiones que nos ayuden a valorar las posibilidades reales de convertirse en realidad. Este esfuerzo nos obliga a reflexionar sobre la idea que tenemos de la esencia, naturaleza o condición humana, así como de los criterios y procedimientos que tenemos que poner en funcionamiento para dilucidar la forma de llegar a un consenso racional sobre la estructura esencial abierta de los humanos. A partir de allí, se podrá dilucidar qué propuestas de mejoramiento de lo humano resultan legítimas y provechosas y cuáles, por el contrario, conllevan el peligro de acercarnos a situaciones de in-humanidad.

Palabras clave: Filosofía, antropología, humanismo, post-humanismo, biotecnología, evolución.

Abstract Current scientific research considers that we are in the brink of overcoming the boundaries of the human in order to get into a new age, called Post-Human or Trans-Human. This article proposes a clarification between these proposals to rethink what is to be consider human, as a well as a series of reflections that may help us to sort out their possibilities of becoming real. This effort forces us to think on the ideas we have about human essence, nature and condition, as well on the criteria and procedures we have to elucidate how to reach a consensus about the essentially open essence of humans. From there, we will be able to decide which proposals are legitimate and beneficial and which ones, on the contrary, entail the danger of bringing us closer to situations of in-humanity.

Keywords: Philosophy, Anthropology, Humanism, Post-Humanism, Biotechnology, Evolution. 


\section{Introducción}

El ser humano, aunque nacido del proceso evolutivo, lo ha traspasado para situarse en ese mundo artificial que llamamos cultura. Somos fruto de dos herencias, la biológica y la cultural. De ahí que siempre se ha sentido mal atrapado en límites y barreras que han pretendido recortar sus posibilidades, sintiéndose empujado por fuerzas que lo mueven a estar siempre más allá de sí mismo.

Si esto ha sido siempre así, la acumulación de saberes, en todas las disciplinas teóricas y prácticas, se ha ido acelerando de tal forma que en la actualidad parecería que estuviéramos al borde de superar la frontera de lo humano para adentrarnos, según opinión de algunos, en una era nueva llamada post-humana o trans-humana. ${ }^{1}$ La denominación es bastante ambigua, puesto que, aunque todas las propuestas apelan a un futuro novedoso para los humanos, la forma de concebirlo y el modo de nombrarlo es diverso según los autores. Además, lo que unos denominan post-humanidad otros lo consideran trans-humanidad, y al revés, siendo muy difícil establecer límites y distinciones en este horizonte futuro que está ya haciéndose presente entre nosotros.

El contenido de estas páginas se orienta a introducir una cierta clarificación dentro de estas propuestas, así como una serie de reflexiones que nos ayuden a valorar las posibilidades reales de convertirse en realidad. De igual forma, en la medida en que estas propuestas se enfrentan a aspectos básicos de nuestra forma tradicional de entendernos como humanos y de establecer los criterios básicos de nuestra convivencia, tendremos que reflexionar sobre la idea que tenemos de la esencia, naturaleza o condición humana, así como de los criterios y procedimientos que tenemos que poner en funcionamiento para dilucidar la forma de llegar a un consenso racional sobre la estructura esencial abierta de los humanos, desde la que tendremos que dilucidar qué propuestas de mejoramiento de lo humano resultan legítimas y provechosas y cuáles no, resultando más bien peligrosos los intentos de acercarnos a situaciones de in-humanidad.

\section{La especie humana entroncada en el proceso evolutivo}

\section{1. ¿Evolución detenida o superada?}

Hoy día tenemos claro que al ser humano no se le puede entender al margen del proceso evolutivo. Somos la última especie que ha emergido de ese proceso, aunque no nos reducimos a ser una especie más, sino que constituimos una especie singular. Pero hay una serie de preguntas que se hacen los estudiosos y la gente en general: ¿sigue 
activa la evolución, o se ha detenido? ¿Tiene futuro la evolución? En realidad, no se ha detenido en la medida en que siguen vigentes los dos motores de la misma: las mutaciones y la selección natural. Pero con la aparición del género humano, y el conjunto de sus diferentes especies, la evolución podríamos decir que ha sido interferida y superada. Interferida, en la medida en que no dejamos que la evolución se desarrolle con los mecanismos naturales que hasta ahora ha seguido, porque curamos enfermedades, ayudamos a sobrevivir a personas débiles y no suficientemente aptas para la supervivencia, entre otras, construyendo un mundo artificial, el mundo de la cultura que tiene valores y normas diferentes a la biología. Superada, puesto que el ser humano va conociendo las leyes de la biología y va teniendo mayor capacidad para interferir en ésta, de tal forma que no necesitamos esperar demasiado tiempo la acumulación de muchas mutaciones para conseguir, por ejemplo, volar, sumergirnos en los océanos, entre otras, sino que somos capaces de curar enfermedades interviniendo en la estructura genética, confeccionar plantas y animales transgénicos, clonarlos, alargar nuestras vidas (soñando incluso con superar la muerte) y, además, nos hallamos a las puertas de pasar de una genética terapéutica a otra eugenésica.
Sobre este último punto es que nos interesa reflexionar, puesto que con el avance de las biotecnologías, o mejor dicho, la confluencia de las nuevas tecnologías [NBIC: nanotecnología, biotecnología, Informática (big data) y cognitivismo informático: IA fuerte], nos estaríamos acercando, según algunos, a una época en que lo humano habría sido superado inevitablemente por lo post-humano o lo trans-humano.

\subsection{La incidencia de las nuevas tecnologías en el proceso evolutivo}

Las nuevas tecnologías $(\mathrm{NBIC})^{2}$ están incidiendo de una forma tan amplia y profunda tanto en las estructuras del mundo de la vida (biotecnologías) como en el ámbito humano (antropotecnias), que nos estamos enfrentando ya, y en mayor medida en un futuro no muy lejano, a decisiones de tal calado social y ético que apenas nos damos cuenta y ni nos atrevemos casi a imaginar. Como decía Alvin Toffler (1973), pareciera como si el futuro nos hubiera llegado demasiado de prisa, abocándonos a una etapa nueva e imprevista de nuestra historia que puede resultar un salto cualitativo respecto al presente, la etapa post/ trans-humana.

De este modo, si a través del proceso evolutivo ha surgido lo humano desde lo pre-humano, como 
consecuencia de una acumulación de mutaciones espontáneas, estaríamos ahora, por el contrario, a las puertas de dejar atrás lo humano para adentrarnos en lo post/trans-humano, debido en este caso a las extraordinarias potencialidades que las nuevas tecnologías están poniendo a nuestra disposición. La especie humana parece con ello capacitada para superarse a sí misma hacia una nueva especie de lo humano, sin que sepamos adivinar hacia dónde nos dirigimos, ni tampoco nos sintamos preparados para controlar este proceso.

Con las biotecnologías, el ser humano se está haciendo notar tanto en el entorno ambiental como también en la propia especie humana, produciendo efectos claramente beneficiosos, pero al mismo tiempo generando riesgos cuyas consecuencias no somos del todo capaces de determinar. La moderna biotecnología, término acuñado en 1919 por Károl Ereky, ingeniero húngaro, ${ }^{3}$ está aplicándose para producir organismos genéticamente modificados (OGM), u organismos transgénicos, esto es, organismos vivos cuyo genoma se ha modificado a través de técnicas de ingeniería genética (Tartaglia y Cirillo, 2016, pp. 79-95). Se trata de introducir en un organismo (sea animal o planta) un nuevo gen (transgén), con objeto de dotar a dicho organismo de la nueva propiedad del transgén, produciendo así grandes ventajas (mayor resistencia a pesticidas, menor posi- bilidad de contaminación, mayor productividad, mayor resistencia a sequías, entre otros), pero sin estar todo ello exento de riesgos y consecuencias negativas a corto o largo plazo (Rifkin, 2009).

Siendo eso muy importante, lo más significativo es que las biotecnologías están en la actualidad utilizándose para intervenir en la mejora y perfeccionamiento de lo humano, convirtiéndose por ello en antropotecnias (Marcos, 2016). Así, las modernas biotecnologías se vuelven hacia su autor, el ser humano, aunque este volverse hacia o sobre lo humano tiene el riesgo de convertirse también en algo contra lo humano. De ahí que, si en el ámbito de la biósfera (tanto en plantas como en animales) nos resulta perentorio introducir la reflexión ética en relación a estos avances técnicos, en el caso de lo humano la necesidad y urgencia de esta reflexión es todavía mayor.

A la hora de enjuiciar éticamente este impacto en lo humano, nos tenemos que mover entre dos posturas extremas: la que considera que todo lo que puede hacerse técnicamente es ético y tiene que ser permitido socialmente, puesto que, según esta postura, lo ético no tiene que meterse en el terreno científico, y la postura que se opone frontal y totalmente a cualquier tipo de innovación. La postura realista intermedia no se opone a la tendencia 
del ser humano a su propia mejora, en todos los ámbitos de su realidad, sino que exige la necesidad de un discernimiento serio para dilucidar entre las mejoras que nos pueden hacer más humanos y las que, con pretensiones de mejorar lo humano, lo sitúan en una dimensión que más que implicar humanidad, lo puede rebajar a niveles de in-humanidad o sub-humanidad.

Como dice L. Ferry (2017):

En este terreno, el auténtico enemigo del pensamiento es la simplificación. Hablar de la "pesadilla transhumanista" es tan profundamente estúpido como hablar de la felicidad o de la salvación transhumanista. Todo es cuestión de matices o, por decirlo más claramente, de límites, de distinciones entre ciencia e ideología, entre curar y aumentar e incluso [...] entre terapéutica clásica y "aumentación terapéutica". En el fondo, siempre acabamos volviendo a la misma pregunta: ¿se trata de que lo humano sea más humano -es decir, mejor, al ser más humano- o lo queremos deshumanizar, engendrando artificialmente una nueva especie, la de los posthumanos? ( $p$. 17).

\subsubsection{Dimensión terapéutica $y$ eugenésica de las antropotecnias}

A la hora de hacer esta reflexión, tenemos que comenzar distinguiendo, dentro de las antropotecnias, las que se sitúan en la vertiente terapéutica y las que apuestan por una línea eugenésica y utópica, más difícil de controlar. ${ }^{4}$ Dentro de la vertiente terapéutica se suelen señalar tres: la diagnosis y el consejo genético, la farmacopea genética y la cirugía o ingeniería genética. Por su parte, al hablar de las propuestas utópicas y eugenésicas también se suelen señalar tres: los intentos de alargar el envejecimiento, soñando incluso con la posibilidad de llegar a ser inmortales, la selección germinal y la clonación de individuos.
No podemos detenernos en cada una de estas diferentes antropotecnias, sino tan sólo hacer algunas observaciones sobre las tres propuestas eugenésicas. En relación al alargamiento de la vida y la posibilidad de vencer a la muerte (la muerte de la muerte), nos referiremos cuando hablemos de Bostrom $y$ otros autores que la proponen y defienden. Pero hemos de decir, de entrada, que por más que la medicina consiga retrasar el ritmo de envejecimiento celular, en la medida en que los humanos vivimos en un universo que tiene fecha de inicio y también de caducidad, consecuencia de la ley de la entropía, segunda ley de la termodinámica, difícilmente se puede imaginar una especie humana inmortal en un universo que se 
apagará y desaparecerá, aunque sea después de una cifra tan astronómica como la que nos indica su fecha de nacimiento tras el Big Bang $(13,500$ millones de años).

Respecto a la clonación, cada vez hay un consenso mayor que la clonación de un individuo humano es imposible. No porque no se posea, o se pueda poseer, una tecnología capaz de conseguirlo, sino porque la individualidad humana no es producto sólo de los genes. De tal modo que, como indica claramente $R$. Lewontin: "podremos clonar un gen, podremos clonar un genoma, pero no se puede clonar una persona". De ahí que el mismo R. Lewontin indica significativamente: "Aunque puede haber genes para la forma de nuestras cabezas, no puede haberlos para la forma de nuestras ideas" (Lewontin, 2001, p. 26). Se han clonado, de hecho, genes y genomas, pero no individuos, porque las personas somos una síntesis de genes, ambiente y autonomía individual. Así, un mismo genoma humano, situado de nuevo en el proceso embrionario y vital, sería alguien totalmente diferente. Cada uno de nosotros somos el conjunto de circunstancias (genéticas y ambientales) que, entrelazadas con nuestras decisiones personales, han ido conformando el relato de nuestra biografía, relato en sí mismo irrepetible. Por eso, cuando se habla de naturaleza humana, sobre todo cuando se entiende por naturaleza los rasgos específicos y exclusivos del genoma, se está incurriendo en una simplificación y en un recorte tal de nuestra realidad que sólo puede ser defendido por ignorantes, o por alguien muy partidario del biologismo antropológico reduccionista. Está claro que dos genomas idénticos darán lugar, debido a sus influencias culturales, a dos individuos humanos muy diferentes. Por otro lado, igual apreciación tenemos que hacer en relación a plantas y animales, porque un mismo genoma se comporta de diferente forma si cambia de forma importante el entorno ambiental (Lewontin, 1984). La conclusión es evidente: se pueden clonar genes, incluso un genoma, pero nunca un individuo.

La referencia a la intervención en la selección germinal humana es la parte más peligrosa de las antropotecnias, en la medida en que propone rebasar la estructura genética de los humanos con ánimo de mejorar nuestra especie, tales sueños suponen poner en riesgo nuestra realidad y los valores sobre los que construimos nuestra humanidad. Si las pretensiones de perseguir la inmortalidad y de conseguir la clonación de un ser humano se enfrentan y nos sitúan ante la cuestión de la naturaleza humana, en mayor medida lo hacen las pretensiones de los más audaces de introducir cambios en la estructura germinal humana, como tendremos ocasión de verlo de la mano de J. Habermas y de M. Sandel. 
Si nos referimos, por otro lado, a la dimensión ética, tendríamos que tener una razón de peso para justificar la propuesta de clonar una persona humana. A veces se intenta justificar esta pretensión por el deseo de unos padres de reproducir un hijo muy querido fallecido, o también por el deseo ingenuo de reproducir individuos especialmente notables por su saber o ejemplaridad (científicos, políticos y deportistas). La sensibilidad moral de la sociedad actual tiene prohibida legalmente la clonación de humanos, resultando aterradora la posibilidad de que se puedan reproducir cientos o miles de individuos con una estructura genómica idéntica. Autores como el premio Nobel Jean Dausset, que se han destacado por sus reflexiones críticas sobre la ética de la investigación científica, consideran que la técnica de la clonación humana puesta en manos de ciertos indi- viduos poseería una capacidad de destrucción de los valores humanos semejante al peligro que supondría una guerra nuclear (Ayala y Cela Conde, 2006, p. 178). En definitiva, como afirma L. Ferry: "La clonación de humanos sería en estos momentos -aunque sólo fuera por razones técnicas- una barbaridad ética e incluso un acto criminal" (Ayala y Cela Conde, 2006, p. 173).

Pero como parece evidente que entre los humanos no es suficiente contentarse con afirmar que determinadas conductas son éticamente reprobables, se tiene que promover también una reflexión sobre los beneficios y peligros de la biotecnología, con objeto de delimitar bien claramente aquello que resulta favorable y un avance para las vidas humanas, y lo que supone o supondría serios riesgos para su bienestar y dignidad. En definitiva:

\begin{abstract}
Por decirlo de una forma literaria, el reino de la luz y el reino de las tinieblas forman el horizonte de la humanidad; es preciso asegurarse de que, tratando de llegar a la ciudad de la Utopía, no tomamos el camino hacia la autodestrucción o el infierno. (Ayala y Cela Conde, 2006, p. 179.)
\end{abstract}

\title{
2. Diferentes tipos de post/trans-humanismos
}

La primera tarea que debemos hacer es establecer una cierta clarificación entre las diferentes propuestas post/trans-humanistas. Aunque la intervención de los humanos sobre la naturaleza y sobre sí mismos para introducir mejoras viene de muy lejos, las extraordinarias capacidades que la tecnociencia posee en la actualidad hacen que nos situemos en una época cualitativamente nueva. La utilización de la técnica ha sido una constante en la historia de los humanos. Como indica 
A. Marcos (2010): "nuestra propia evolución biológica no se entendería sin la técnica" (pp. 181-208 y 192), interviniendo en nuestra historia humanizadora desde el homo habilis hasta la actualidad. El género humano ha construido un mundo artificial a partir del ambiente natural en el que ha vivido. Pero lo mismo podemos decir del empeño por conseguir mejoras sobre sí mismo, potenciando sus capacidades naturales. Lo ha hecho a través de cultivar sus potencialidades por medio de la educación y de otras instituciones sociales, con las que las diferentes culturas han ido introduciendo todo tipo de mejoras y aprendizajes en los humanos: escritura, costumbres sociales, políticas, religiosas, artísticas, deportivas, entre otros. Se trataba de mejorar la naturaleza con hábitos culturales que conformaban una segunda naturaleza: "Esta segunda naturaleza, gestada libremente por cultivo, no niega ni anula la primera, sino que la respeta, la toma muchas veces como canon, la orienta y la integra" (Marcos, 2010, p. 193).

Pero, como estamos viendo, en la actualidad las nuevas potencialidades de las antropotecnias nos sitúan en una nueva etapa de mejora y transformación. Así, esto es lo que está suscitando que muchos hablen de estar a las puertas de una nueva era: la post-humana o trans-humana. Intentando clarificar estos conceptos, podemos distinguir tres ámbitos o tipos de propuestas:

a) El post-humanismo zoocéntrico o biocéntrico, que defiende la superación de la etapa humanista o antropocéntrica, desde la negación de la diferencia ontológica entre los humanos y el resto de los animales. Para esta forma de pensar, el ser humano se habría dado cuenta, por fin, de que no es más que una especie animal más, cuya diferencia con las otras es sólo cuantitativa, no cualitativa.

b) El post-humanismo biónico, que persigue la mejora de lo humano utilizando las posibilidades que le dan las nuevas tecnologías. No le interesa difuminar la frontera entre lo humano y lo pre-humano (animal), sino utilizar los avances de las nuevas tecnologías para construir un nuevo tipo de hombre que vaya superando las limitaciones y deficiencias que nos ha impuesto la biología.

c) El trans-humanismo robótico o imformático, que persigue no tanto mejorar lo humano, sino superarlo a través de construir humanos artificiales, los robots - androides/ginoides, que representan de algún modo 
una extensión de lo humano, en la medida en que llegarían a tener nuestras mismas características y potencialidades pero, al mismo tiempo, superadas desde una ingeniería informática que habrían dejado obsoletas y limitadas las capacidades de los humanos biológicos.

\subsection{El post-humanismo naturalista, o zoocéntrico/biocéntrico}

Crece cada vez más en nuestro entorno cultural la pretensión de que la concepción humanista y antropocéntrica está superada, sobre todo a partir de la propuesta evolutiva darwiniana. Según ello, somos una especie animal más, y la diferencia con las demás es sólo cuantitativa, en absoluto cualitativa. Tras haber superado las épocas en la que nos percibíamos en relación a Dios (teocentrismo), o desde la comparación entre culturas humanas (antropocentrismo), estaríamos ya en una tercera etapa, la zoocéntrica o biocéntrica, en la que los humanos tenemos que buscar nuestra identidad viéndonos en relación con los animales.

Los post-estructuralistas y los anti-humanismos reduccionistas han venido proclamando desde hace décadas la muerte del hombre y su disolución en el resto de la realidad, en un horizonte plano de valor $y$ sentido. En esa línea de-constructora de lo humano y de su centralidad sobre el resto de los seres vivos, se sitúa la tendencia actual zoocéntrica, que declara difuminada y borrada la frontera entre lo humano y lo animal. El darwinismo, según ellos, nos hizo tomar conciencia de la incardinación de nuestra especie en la biósfera, aunque eso no suponía necesariamente negar el valor o diluir la centralidad de lo humano en el mundo de la vida. Esa es una de las posibles interpretaciones, la biologista y reduccionista, pero el darwinismo, en cuanto teoría científica, permite también defender legítimamente un nuevo humanismo. De hecho, cuando a partir de Darwin se incrementaron las investigaciones sobre la diferencia entre hombres y animales, se dieron dos interpretaciones contrapuestas: la etología de K. Lorenz, Tinbergen y von Frisch, y luego la sociobiología, de tendencia reduccionista, y la otra corriente -conformada por los iniciadores de la moderna antropología filosófica, M. Scheler, H. Plessner, H. Gehlen, entre otros- consideran que lo específico de lo humano es precisamente lo que nos diferencia de los animales (Beorlegui, 2009, Cap. 6). Si la primera corriente pretende disolver la diferencia ontológica entre animales y humanos, la segunda trata de mostrar en las mismas características biológicas del desarrollo evolutivo de los animales más cercanos a los humanos, los anticipos de lo que van a ser las diferencias esenciales entre ellos: la menesterosidad biológica, la inespecialidad conductual, la neotenia, 
el aumento progresivo del cerebro, entre otros (Prieto López, 2008).

Estos dos enfoques tan contrapuestos se siguen manteniendo en la actualidad, asentado más firmemente el primero, el reduccionismo biologista, con el aumento progresivo de una nueva sensibilidad ecológica y animalista. En esta línea se sitúa el movimiento pro liberación animal, liderado por P. Singer, H. Tristam Engelhart y J. Harris, entre otros, quienes ponen en cuestión la dignidad humana y su diferencia ontológica en relación al resto de las especies vivas, pidiendo una reconsideración de los grandes problemas de la bioética. En forma similar o de mayor radicalidad en esta dirección se observa en muchos investigadores del comportamiento animal, quienes desde ámbitos como la primatología, la etología cognitivista, la psicología evolucionista y otras disciplinas científicas similares, consideran que las diferencias entre humanos y animales, no sólo en aspectos morfológicos y fisiológicos, sino también en mentales y comportamentales, no son suficientes como para concluir y defender una diferencia cualitativa, sino meramente cuantitativa. Uno de los más beligerantes a la hora de defender estas tesis está siendo en la actualidad el primatólogo holandés Franz de Waal, para quien la complejidad mental y los mecanismos comportamentales de los animales más cercanos a nosotros, como los primates, son tan similares a los humanos que la diferencia sería sólo cuantitativa (De Waal, 2016). ${ }^{6}$ Estos autores consideran, en definitiva, que nos hallamos al inicio de una época post-humanista, en la que se tienen que superar la visión antropocéntrica que los humanos hemos venido defendiendo desde siglos atrás, para convencernos de que somos una especie más, sólo que más evolucionada, con una mayor complejidad sensitiva a la hora de recibir información del ambiente y responder a sus estímulos, pero en absoluto diferente de forma cualitativa.

Pero no es esta línea posthumanista la que más nos interesa describir aquí, sino más bien las que proponen un nuevo tipo de ser humano como consecuencia de la aplicación de las biotecnologías y antropotecnias a nuestra especie, o bien la construcción de androides/ ginoides a los que se les podría atribuir la categoría de personas.

\subsection{El post-humanismo biónico}

La primera de esas propuestas es la del post-humanismo biónico (hombres cyborgs), que pretende, con ayuda de las nuevas tecnologías, ir consiguiendo, en un futuro no muy lejano, una mejora o biomejora (human enhancement) de lo humano en múltiples aspectos. Se trata de construir un nuevo tipo de ser humano, diseñado y potenciado por las biotecnologías y las antropotecnias, que marcaría una etapa nueva de la historia de lo 
humano. La cuestión de fondo es si estas mejoras, que comenzarían por curar enfermedades y aliviar dolencias y carencias, podrían desembocar incluso en cambiar nuestra estructura germinal genética, con lo que nos enfrentaríamos a la cuestión sobre la legitimidad o no de transformar la naturaleza humana, la identidad y el bienestar humano. La difícil y en apariencia pequeña distancia entre usar estas tecnologías con fines terapéuticos y hacerlo con fines eugenésicos nos sitúa ante la necesidad de discernir con detenimiento sobre la legitimidad y conveniencia o no de estas praxis. Por otro lado, se nos exige reflexionar sobre el riesgo que su uso pueda suponer una fuente de discriminación, segregación y de aumento de las distancias entre los diferentes grupos y capas sociales, pudiendo unos humanos tener acceso a estas mejoras, mientras que el resto mayoritario podría quedar totalmente al margen de sus beneficios.

A la vista de esta compleja problemática, no podemos extrañarnos de que se estén dando respuestas y posicionamientos muy variados y divergentes. Se suelen distinguir tres posturas: los defensores, los opositores radicales y los que las aceptan en parte, aunque consideran que tiene que valorarse su uso y poner límites a los excesos.

Dentro de los defensores hay, a su vez, dos grupos: los que consi- deran que su uso está justificado éticamente, y los que no sólo lo ven éticamente justificable, sino que su utilización constituye, además, una obligación moral, puesto que si algo es bueno es una obligación tratar de conseguirlo.

En cambio, entre los que se oponen al mejoramiento están los que se apoyan en posturas esencialistas, entendiendo que con ello se violaría y se alteraría la naturaleza humana y su esencia intrínseca.

La tercera postura se sitúa en un ámbito intermedio, enjuiciando cada tipo de mejora de forma concreta, unos lo hacen desde posturas deónticas (basadas en unos límites éticos a la hora de entender lo humano), y otros desde posturas utilitaristas y consecuencialistas, esto es, no apelan tanto a la maldad o bondad intrínsecas de la mejora, sino más bien a las posibles consecuencias negativas que tendría sobre la sociedad. Lo problemático es si se podría hablar de lo segundo (las consecuencias) si no se tiene claro lo primero (lo bueno o malo en sí).
a) Defensores de las propuestas de mejoramiento

El origen remoto del posthumanismo/trans-humanismo, en su ambigüedad de contenidos, se suele situar en un texto de Julian Huxley, hermano de Aldous Huxley, gran divulgador científico y primer director 
de la UNESCO, quien defendía la capacidad humana de trascenderse, utilizando para esta tarea el nombre de trans-humanismo. Lo que persigue este trans-humanismo es simplemente la mejora del ser humano (human enhancement) para conseguir un estado superior o post-humano. Se sienten continuadores de la mejor tradición humanista del pasado, que persigue lo mejor para el ser humano como especie y para cada individuo en particular, promoviendo el pensamiento racional, la libertad y la tolerancia. Para ello, consideran conveniente y posible echar mano de la convergencia de las grandes tecnologías. Siendo una tendencia tan nueva y tan llena de ramificaciones, no es extraño que dentro de ella militen personas y grupos de muy distinta ideología, y con objetivos muy diferentes, encontrándose entre ellos personas radicales, frívolas y hasta provocadores. Pero también se encuentran entre ellos personas serias, que tratan de fundamentar su postura con argumentos filosóficos de peso, encaminados a justificar la mejora humana, incluso en el caso de que nos lleve a superar nuestra condición actual, puesto que para ellos, la humanidad actual no tiene por qué ser la etapa final de la evolución, sino más bien un inicio hacia otra forma de ser humanos, la post-humanidad.

Uno de los referentes y líderes más importantes de la propuesta post-humanista es Nick Bostrom, para quien la utilización de las antropotecnias no sólo es legítima, sino una obligación moral. Se ha hecho muy conocida su propuesta de superar la muerte, a través de la Fábula del Dragón (Bostrom, 2005, pp. 273-277). La muerte se presenta a los humanos bajo la figura de un gran dragón, que exige cada año miles de víctimas a la humanidad. No obstante, el dragón puede ser vencido, y es una obligación moral poner todos los medios para vencerlo, la muerte. Ahora bien, se trataría de extender la vida en condiciones saludables. Es posible que, cuando se consiga llegar a la etapa post-humanista, podamos pensar y comportarnos de forma diferente a como lo hacemos los humanos, y guiarnos por valores diferentes, cosa que no deja de ser inquietante. Así, no todos los transhumanistas están dominados por un optimismo ingenuo, ni parecen dar la espalda a los peligros y riesgos que conlleva el uso irreflexivo de las nuevas tecnologías, sino que son conscientes de la necesidad de reflexionar para tomar decisiones sabias y acertadas que nos ayuden a mejorar nuestra situación, evitando los peligros que nos acechan.

Otro de los autores de referencia es Julian Savulescu, cuya postura se resume, en primer lugar, en que todos los humanos buscamos mejorar en todos los aspectos, físicos, psíquicos y morales, por lo que según él, no solamente es correcto utilizar estas nuevas tecnologías para ello, sino 
que constituye una obligación. Por tanto, si consideramos legítimo y obligatorio curar enfermedades, debemos aceptar la mejora de lo humano en todos sus aspectos, pues la línea divisoria entre enfermedad, discapacidad y malestar (en un sentido amplio) es muy borrosa, dada la amplitud semántica del término salud. Así, Savulescu propone, en la línea de los cuatro principios de la bioética, el principio de beneficencia procreativa, consistente en la obligación de los padres de seleccionar, a la hora de tener hijos, al niño que pueda tener la mejor vida posible, utilizando para ello la mejor información genética disponible (Savulescu, 2002, pp. 413-426). El problema que plantea esta propuesta es cómo definir la mejor vida, puesto que nos adentramos (como ocurre con el principio de beneficencia de la bioética) en la gran pluralidad de definiciones de bien y de vida buena. Independientemente de ello, Savulescu considera que los padres tienen la obligación de buscar al mejor hijo posible, y no hacerlo sería inmoral. Por otro lado, no considera un argumento de peso el que, en el empeño de programar seres posthumanos, más allá de la naturaleza humana, podamos construir seres inhumanos o subhumanos, porque la libertad siempre tiene sus riesgos y no se puede prohibir la libertad de elección, al menos en una democracia liberal. En definitiva, más que proponer medidas restrictivas, hay que promover, según estos autores, leyes y medidas adecuadas para promover estas mejoras, procurando que no perjudiquen a los humanos.

Esta postura es la que se denomina eugenesia liberal, que consiste en defender no sólo la legitimidad ética del uso de las antropotecnias, sino la obligación moral de utilizarlas, dejando la decisión de su uso en manos de cada individuo. Para el logro de esta utópica tarea, los transhumanistas consideran que se tienen que defender y potenciar valores como la libertad individual y la capacidad de elección de las tecnologías de mejora que se consideren oportunas, lo que supone vivir en una sociedad que respete la pluralidad de opciones en este campo, puesto que cada persona tendrá un modelo de mejora diferente, sin que sea razonable ni legítimo imponer uno solo para todos. Para conseguir esto, se necesita que la sociedad discuta libremente de estos temas, vaya clarificándose cada vez más en esta problemática y respete la pluralidad de opciones que sobre este punto se dan y se darán (Feito Grande, 2011, pp. 226-227).

Ahora bien, dentro de esta tendencia liberal (ultra-liberal), se suelen distinguir dos posturas: la conservadora, para quien la libertad de elección dependerá de los medios económicos de cada uno, no considerando un problema que una minorías ricas puedan beneficiarse de estas tecnologías, mientras que la mayoría 
de la gente lo haga de un modo restringido, o incluso no pueda tener acceso a ninguna mejora. La segunda postura es la progresista o socialigualitaria, defiende, en cambio, un acceso democrático e igualitario a las antropotecnias, por lo que considera que, a diferencia de las utopías eugenésicas de tiempos anteriores, que se imponían desde arriba, desde instancias dictatoriales (como el nazismo y otros regímenes que buscaban la mejora genética), ahora se daría un acceso igualitario y libre, por lo que habríamos alcanzado la utopía social que los humanos veníamos persiguiendo desde siempre.

\section{b) La postura bioconservadora}

Esta postura está representada, entre otros, por F. Fukuyama (2002) y por Leo Kass, quienes consideran el trans-humanismo como la idea más peligrosa del mundo (Fukuyama, noviembre de 2004), porque el ser humano tiene una esencia y cualquier transformación de la misma a través de las antropotecnias sería un atentado contra la dignidad humana. Define la naturaleza humana como un conjunto de características comportamentales, junto con otros rasgos propias de la especie humana, rasgos que se deben a factores genéticos más que a factores ambientales (Fukuyama, 2002, p. 214). Así, junto a los elementos accidentales que confluyen en cada persona, lo que importa son los rasgos genéticos que conforman la esencia de lo humano, y que no se pueden tocar, porque constituyen la base y el apoyo de la dignidad humana (Fukuyama, 2002, p. 243), de ahí la exigencia de ser tratados todos los humanos con justicia e igualdad.

Leon Kass defiende ideas similares. Para él, los cambios que las antropotecnias pueden introducir en los humanos no nos producirían mejoras dignas de lo humano sino que acabarían por deshumanizarnos, privándonos del sentido del ciclo vital, del sentido del sexo o del trabajo. Estas argumentaciones las basa en la sabiduría de la repugnancia, inspirada en la propuesta de H. Jonas (1994) sobre la heurística del miedo, que vendría a ser, según Leon Kass, como una especie de intuición emocional que nos surgiría de una sabiduría profunda, más allá de la lógica racional (Kass, 1997, p. 22).

Todos los autores de esta postura bioconservadora coinciden en razones parecidas a la oposición a las antropotecnias: apelar a una esencia humana inmutable, de la que se deduce el fundamento de la dignidad humana; achacar a los defensores de las antropotecnias el vicio de soñar y de jugar a ser como dioses, creadores y superadores de las fronteras de lo natural, lo que suele conllevar a peligrosas consecuencias. Se deben considerar, por tanto, estas prácticas intrínsecamente malas e inmorales por pretender romper los límites de lo 
natural, que es lo que marca el perfil de lo bueno y digno de lo humano. Es comprensible que esta postura no se detenga tanto en analizar las consecuencias negativas de la utilización de las biotecnologías y antropotecnias porque su reparo se sitúa antes, en la raíz del problema: intervenir en cambiar los límites de lo natural es malo $\mathrm{y}$, por tanto, no hace falta discernir entre intervenciones positivas o éticas y las que no lo son, porque todas son negativas. El orden interno de lo natural es bueno, y no debe cambiarse. Hay que someterse a las leyes del azar mutacional, los cambios espontáneos de la naturaleza, pero no es legítimo que el ser humano introduzca cambios en la naturaleza a través de lo que sería un diseño racional, que alteraría el orden sabio de la naturaleza, consecuencia de la hybris, de la desmesurada ambición y del sueño humano de jugar a ser dios.

$\mathrm{Y}$ ante quienes puedan argumentar que habría que distinguir entre cambios legítimos frente a otros más graves e irreversibles, argumentan que para evitar el peligro de la pendiente resbaladiza, al abrir la puerta a innovaciones menores que llevarían poco a poco a situaciones irreversibles, sitúan su rechazo ya desde el inicio. ${ }^{8}$ Además, para advertirnos de estos peligros describen utopías negativas post-humanistas, en las que se verían las discriminaciones y desigualdades sociales que el uso de estas tecnologías podría generar, por lo que proponen legislaciones que cataloguen y castiguen estas prácticas como crímenes contra la humanidad (Annas, Andrews e Isasi (2002, pp. 151-178). Nos advierten también de la posibilidad de que vivamos una situación en la que la nueva especie de posthumanos se imponga sobre los humanos normales e inferiores, y los maten o los utilicen como esclavos.

c) La postura moderada: J. Habermas y M. Sandel

J. Habermas, desde posturas post-metafísicas, denuncia la utilización de la tecnología genética en la búsqueda de la mejora de los humanos, aunque no de forma indiscriminada, alertándonos de la peligrosidad de cruzar determinadas líneas rojas que traerían serías y peligrosas consecuencias para la humanidad (Habermas, 2002). El principal peligro que Habermas ve en las antropotecnias de mejora de lo humano se halla en que borraría la diferenciación entre lo subjetivo y lo objetivo, rompiendo la simetría entre los humanos, puesto que la capacidad programadora de los padres se situaría en un nivel superior al de los hijos programados. En la medida en que no respetamos la forma de funcionar de la naturaleza que se regula a sí misma a través de procesos azarosos, introducimos una actitud de dominación sobre ella, en función del poder que nos dan 
las cada vez más potentes antropotecnias, rompiéndose de este modo la simetría racional en la que se sitúa la toma de decisiones morales, así como la autocomprensión de la esencia de lo humano.

Para Habermas está claro que las sociedades liberales se orientan, más que hacia la búsqueda de decisiones morales desde una racionalidad comunicativa que busca conjuntar la autonomía con lo universalizable, hacia una libertad individual que pretende no ser coartada por instancias sociales y políticas. De este modo, no ven problema en que los padres pidan tener libertad total en el futuro para elegir el perfil de sus hijos que consideren más adecuado, para llevar una vida de mayor bienestar. Pero de esa forma, se impone una racionalidad instrumental y mercantil, que busca ante todo que cada uno pueda elegir entre las diferentes ofertas que le ofrece el libre mercado, más bien que preocuparse de perseguir las decisiones morales más adecuadas y legítimas salidas de un consenso racional entre personas morales, consenso basado en intereses universalizables, y no tanto en ejercer la libertad sin restricciones dentro del gran mercado tecnológico que nos ofrecerá en el futuro la sociedad de consumo. Por otro lado, como ya lo hemos indicado, se rompería la autocomprensión que tenemos de la especie humana, en la medida en que nos situaríamos en asimetría con los demás humanos. Si tenemos en cuenta la imagen que los humanos tenemos de nosotros mismos, advertimos que, por un lado, somos fruto de un proceso natural en el que no intervenimos (somos generados) y, por otro, construimos la convivencia social y moral en diálogos comunicativos orientados a consensuar las normas básicas morales con las que construimos la convivencia social. Si nos dejamos llevar por la eugenesia liberal se produciría, según Habermas, una distorsión entre la asimetría genética y la simetría moral y social, esto es, los padres se situarían en un nivel superior e irreversible sobre sus hijos, creados y diseñados por el proyecto de sus progenitores, produciéndose un tipo de seres humanos que podrían poner en cuestión la simetría moral de la racionalidad comunicativa. Habríamos pasado, por tanto, de una especie humana generada a otra progresivamente creada por el diseño libre de los padres, dificultando la capacidad de que el hijo, programado y diseñado por sus padres, llegue a comprenderse y vivirse como el autor de su propia vida, sino más bien como el realizador de los sueños de sus padres. Los críticos de Habermas consideran que esa dependencia de los hijos respecto a sus padres ya se da en el proceso educativo y cultural, pero Habermas responde que la influencia social y educativa puede cambiarse, mientras que los cambios genéticos serían irreversibles. 
Nos hallamos, como puede verse, ante cuestiones de hondo calado y enorme dificultad, al mismo tiempo que de una trascendencia vital, puesto que estamos hablando de nuestra propia naturaleza y del futuro de nuestra especie. Ante estas cuestiones tan trascendentales nos hemos dado cuenta, como nunca antes, de la gran pluralidad de planteamientos que se dan sobre la esencia de lo humano, así como de los pilares fundamentales desde los que conformamos la comprensión del mundo y el sentido de la vida y del universo. De ahí que, según esos trasfondos antropológicos y cosmovisionales, nos parecen más correctas y legítimas unas posturas que otras. Así, aunque la postura de Habermas pueda parecer a algunos de gran sensatez, puede parecer a otros insuficiente o totalmente incorrecta. Según ello, como indica L. Feito:

Un transhumanista, convencido de que la tecnología nos permite ser dueños de nuestra vida, respondería a Habermas que sería un error que un individuo no creyera que no tiene elección sobre su propia vida sólo porque sus genes hayan sido seleccionados por sus padres, ya que tiene la misma que si su constitución genética fuera el resultado del azar. Y podría darse la circunstancia de que tuviera una mayor autonomía y posibilidad de elección si las modificaciones realizadas hubieran ampliado el conjunto de sus capacidades básicas. Tener más salud, más inteligencia o más talento es, según los transhumanistas, algo que abre oportunidades para la vida (Feito Grande, 2011, p. 234).

La diferencia está en que los rasgos que nos definen los recibimos de la naturaleza (a la que no tiene sentido objetar) mientras que, en las propuestas post-humanistas, los responsables de nuestras características serían los padres, adquiriendo una responsabilidad ante sus hijos que no sería fácil de administrar y que hasta el presente nunca se había dado.

De todos modos, la cuestión filosófica y ética que está de fondo apunta más bien al procedimiento que habría que seguir para tomar las decisiones adecuadas sobre estos temas tan trascendentales. Los defensores de la eugenesia liberal consideran que los padres pueden programar hijos a la carta, esto es, personas diseñadas desde una libertad total, apelando al principio de autonomía de la bioética, aunque entendido de un modo sui generis. El problema está en que, en la referencia al principio de autonomía de la bioética, confunden la autonomía, entendida en el sentido de la ética autónoma kantiana, con la libertad absoluta de los individuos a la hora de tomar decisiones. Así, la autonomía kantiana, complementada con 
La teoría de la racionalidad comunicativa de Apel y Habermas, no supone apelar a la libertad individual sin restricciones (como ocurre en el existencialismo radical de Sartre), sino más bien saber conjugar, como nos indica el imperativo categórico, la elección personal con los intereses universalizables de los demás humanos. Así, la ética autónoma no consiste en hacer lo que a cada uno le dé la gana, sino que nos exige tomar decisiones racionales, universalizables (hay que decidir aquello que pueda servir para cualquiera en nuestra misma situación), no arbitrarias, en la línea del primer Sartre (para él, yo no elijo hacer algo porque es bueno, sino que es bueno porque lo decido yo) y del liberalismo radical (cada uno puede decidir lo que quiera, sin que la sociedad ni el Estado puedan prohibírmelo, ni tener que responsabilizarme de nada ante los demás) (Cortina, 1993, pp. 223-240).
Todas estas discusiones y diferencias necesitan para dirimirse tener en cuenta la idea que cada uno maneja de naturaleza/condición humana, puesto que ahí es desde donde tiene sentido sustentar y construir la normativa ética desde la que habría que poner orden en el uso de estas nuevas tecnologías. Volveremos sobre este punto tan básico y tan delicado más adelante.

M. Sandel, profesor de la Universidad de Harvard y adscrito en cierta forma al comunitarismo, se opone, como Habermas, a la eugenesia liberal, aunque con argumentos algo diferentes. Su oposición se basa en que, con la programación genética de los hijos, dejaríamos de entender la vida como un don, dejándonos dominar por la hybris, la soberbia prometeica de creernos como dioses.

El problema de la eugenesia y la ingeniería genética, en opinión de Sandel, es que representan un triunfo unilateral de la voluntad sobre el don, del dominio sobre la reverencia, del moldeo sobre la contemplación (Sandel, 2015, p. 139).

El propio Sandel reconoce que esta propuesta puede entenderse con facilidad desde el enfoque religioso (querer imitar el acto creador de Dios por los que usan las antropotecnias con sus hijos o con ellos mismos), pero considera que "la religión no es la única fuente de razones para valorar lo recibido" (Sandel, 2015, p. 139), puesto que pueden entenderse sus ideas desde un enfoque secular. Para él, cuando los humanos no percibimos nuestras capacidades y logros como algo recibido sino como resultado de la revolución genética, destruimos tres elementos que considera básicos en nuestro horizonte moral: la humildad, la responsabilidad y la solidaridad. 
En la situación en que vivimos actualmente los humanos: "la crianza es una escuela de humildad", porque educamos y formamos a nuestros hijos aceptándolos como son, sin que los hayamos elegido. Esta situación se debe extender, piensa Sandel, a todos los aspectos de la vida, porque es una invitación a aceptar lo inesperado y a dominar el ansia de control. El ser conscientes de que nuestra forma de ser no es del todo obra nuestra, mantiene a raya nuestra hybris. Si consiguiéramos con la biotecnología construirnos totalmente a nosotros mismos, nos veríamos totalmente responsables de todos nuestros logros, en vez de estar en deuda por los dones recibidos, y los hijos programados genéticamente estarían en deuda con sus padres, en vez de ser un don del azar, de la naturaleza o de Dios.

El uso de la optimización genética aumentará nuestra responsabilidad en "proporciones intimidantes". Los padres se convertirán en responsables de elegir de una $u$ otra forma a sus hijos. Una de las ventajas que ve Sandel en ser creaturas de la naturaleza o de Dios es que "no somos plenamente responsables de cómo somos" (Sandel, 2015, p. 141). Así, cuanto más dueños somos de nuestra dotación genética, tanto más crece la responsabilidad sobre nosotros y las personas que programamos. Eso tiene consecuencias en todos los aspectos de la vida, incluso en el deporte porque, como dice Sandel, cuando un jugador de baloncesto falla un tiro se le puede culpar por no entrenar, pero en el futuro se le acusará por no ser más alto; y lo mismo pasará ante un jugador que no quiera utilizar sustancias que mejoren su rendimiento y quiera "jugar a pelo". Lo que antes quedaba en manos del azar, se convierte ahora en campo de elección. Y esta tendencia se convertirá en una presión social sobre los padres que no quieran hacer uso de los test prenatales y demás biotecnología, de tal forma que ya no serán "libres para escapar a la carga de decisión que crea la nueva tecnología" (Sandel, 2015, p. 143). Es que el impulso prometeico es contagioso, considera Sandel, pues ya nadie será bien visto por "jugar a pelo" y por "ir a ciegas" al rehusar la utilización de estas nuevas técnicas de selección genética.

Por último, al lado de aumentar nuestra responsabilidad, se "podría reducir nuestro sentido de la solidaridad hacia los más desafortunados" (Sandel, 2015, p. 144), en la medida en que, cuando vivimos nuestra vida como hijos del azar, nos sentimos empujados a compartir nuestro destino con otros. Es lo que ocurre con los seguros: como no sabemos las posibilidades de enfermar, nos apoyamos unos a otros, favoreciendo a los más débiles, siendo los sanos y los que más viven los que terminan por financiar a los más débiles y de vida más corta. "El resultado es una 
mutualidad por inadvertencia. Las personas ponen en común sus riesgos y sus recursos, y comparten el destino de los demás, incluso en ausencia de un sentimiento de obligación mutua" (Sandel, 2015, p. 144). Y aquí es donde Sandel ve un quiebre moral para nuestra sociedad porque "el mayor peligro, aunque ciertamente más especulativo, es que la práctica generalizada de la optimización genética pudiera dificultar el desarrollo de los sentimientos morales que requiere la solidaridad social" (Sandel, 2015, p. 145). En la medida en que somos el resultado de una lotería genética (como indica John Rawls (1975) en Teoría de la justicia), tenemos obligación de repartir los beneficios de la vida con aquellos que ha sido menos agraciados por la fortuna. Para Sandel, sólo la consciencia clara de que no somos plenamente responsables de nuestros éxitos, sino que somos en gran medida un don de la naturaleza o de Dios, puede salvar a una sociedad meritocrática de la arrogancia de pensar que lo conseguido se debe a su esfuerzo y sus méritos, pensando que los ricos lo merecen más que los pobres (Sandel, 2015, p. 146). Así, si se diera un control genético completo, se vendría abajo la solidaridad que en este momento mantenemos los humanos, al ser conscientes de la contingencia de nuestros talentos y fortunas.

Estos sueños utópicos no son, en opinión de Sandel, más que expresión de "la autoimagen prometeica y exal- tada de la época", al mismo tiempo que tendrán como consecuencia un "cambio en el lugar que ocupa el ser humano en el cosmos" (Sandel, 2015, p. 154), en la medida en que, así como Copérnico y Darwin, y después Freud, habrían hecho bajarse al ser humano de su pedestal de superioridad, tras herir en lo más profundo su narcisismo, estas nuevas tecnologías le estarían devolviendo inesperadamente su papel de ser el centro y el dueño de sí y del universo. Sandel considera que, no cabe duda, hay algo de atractivo en estas propuestas soñadoras en las que la libertad humana parece no estar sujeta ya a nada. Pero eso es, piensa Sandel, una visión equivocada de la libertad humana, puesto que "amenaza con suprimir nuestra apreciación de la vida como don, y con dejarnos sin nada que afirmar o contemplar más allá de nuestra propia libertad" (Sandel, 2015, p. 155). Sin duda, Sandel está siendo consciente de que la libertad humana, que es expresión de nuestra condición y naturaleza, es una síntesis de don y tarea (Beorlegui, 2016, Cap. 5), una mezcla de constreñimiento y autonomía, dada nuestra condición de seres bio-psico-sociales. Claro que estas tesis son deudoras de un concepto de naturaleza humana que no todos comparten, y tenemos que referirnos de nuevo a reflexiones posteriores donde veremos los diversos planteamientos sobre aquello que nos conforma como humanos. Pero lo que sí nos muestran las reflexiones de Sandel, al 
igual que las de Habermas, es que nos hallamos ante dos perspectivas muy distantes a la hora de plantear estos temas tan fundamentales: la concepción anglosajona (y, más en concreto, estadounidense), que prima la libertad sin restricciones en el uso de las antropotecnias, y la orientación más social en la concepción del ser humano y la fundamentación de la ética (más propia del resto del entorno occidental). Si la primera postura centra su objetivo en la absoluta libertad individual, la segunda defiende la necesidad de proponer orientaciones y normas consensuadas por la sociedad para el uso de estas biotecnologías, en la medida en que su mala utilización llevaría a transformar peligrosamente la naturaleza humana, así como los fundamentos sobre los que construimos las orientaciones morales de nuestra vida social.

\subsection{La era del trans-humanismo robótico: la extensión de la humanidad a los androides/ginoides}

Si el post-humanismo biónico nos habla de un nuevo tipo de hombre, construido a base de prótesis de diversos materiales para potenciar sus capacidades, el trans-humanismo robótico pretende construir una réplica de lo humano totalmente artificial. El post-humanismo biónico persigue, pues, mejorar lo biológico, mientras que el trans-humanismo robótico menosprecia u olvida nuestro cuerpo biológico para situar lo humano en lo mental, en la inteli- gencia, y actuar sobre ella. Se trataría, por tanto, de conseguir copiar, o de verter, como si fuera un programa de inteligencia artificial (software) contenido en una memoria USB, la mente completa de un ser humano en un soporte metálico (hardware), dando por hecho que tal máquina inteligente, robot o androide, sería una copia exacta de un ser humano.

Esta proyección utópica hay que situarla dentro de las investigaciones sobre la Inteligencia Artificial (IA), surgidas al calor del rebrotar de las ciencias cognitivas y el funcionalismo filosófico en el ámbito norteamericano, a mitades del siglo $X X$, consecuencia del movimiento de superación del conductismo científico y lógico (Gardner, 1987). El desmarque del conductismo se produjo tanto desde la denominada teoría de la identidad, apoyada en el auge de las neurociencias, para la cual un estado mental se reduce a un estado cerebral, como desde el funcionalismo filosófico, de la mano sobre todo de H. Putnam y J. Fodor, y siguiendo las huellas de Alan Turing, se desmarcan tanto del conductismo (para el cual no existe lo mental; un estado mental se reduce a una descripción conductual) como de la teoría de la identidad (defiende que un estado mental es un estado cerebral), para distinguir entre los estados cerebrales (soportes de lo mental) y los estados mentales (funciones de los estados cerebrales). De esta forma, proponen 
que el mejor modo de entender la relación entre la mente y el cerebro es verlo como la relación que se $\mathrm{da}$, dentro de un ordenador, entre el programa (software) y el soporte metálico (hardware), dando lugar a un fructífero camino a investigar en el terreno de lo que se ha denominado desde entonces IA.

Ahora bien, la propuesta de la IA de asemejar la relación cerebromente con la existente entre softwarehardware se entendió siempre en un doble sentido, débil y fuerte. El sentido débil considera que la doble perspectiva de los ordenadores es un símil que nos permite entender ciertos parecidos y diferencias entre lo cerebral y lo mental, sin que tales parecidos/diferencias se reduzcan sólo a eso, así como construir programas de ordenador que simulen y se asemejen al modo de comportarse de la inteligencia humana. Por el contrario, la IA en sentido fuerte, siguiendo las directrices del denominado test de Turing, tiene el convencimiento de que se podrán construir máquinas inteligentes que serán exactamente iguales a la mente humana, de tal forma que, como defienden algunos teóricos de ingeniería informática, no se ve por qué habría que negarles, en consecuencia, la consideración de personas (Ross Anderson, 1984; Turing, Putnam y Davidson, 1985 y Copeland, 2013).

Para las tesis funcionalistas, como ya dijimos, los estados mentales se reducen a funciones de los estados cerebrales, por lo que no hacen hincapié en la centralidad y consistencia de la mente humana como agente autónomo y libre, por lo que, a pesar de sus críticas al conductismo, siguen de alguna forma contagiados del rechazo de Skinner a la sustancialidad de la conciencia y de la subjetividad humana (Skinner, 1982). Reducido lo corpóreo a su cerebro, que a su vez queda relegado a mero soporte de las capacidades procesadoras de la mente informática, "el cerebro humano será superado por el artificial en cuanto la complejidad de éste crezca, ya que el cerebro humano es simplemente una máquina de carne. Por ello, propone la copia del cerebro para que sus funciones fueran realizadas por circuitos integrados" (Ballesteros, S. F. p. 34), pero de esa forma, el funcionalismo filosófico no acierta a explicar la dimensión subjetiva de lo mental, esto es, la capacidad de introspección, la mirada de primera persona que, aunque sea susceptible en ciertas ocasiones de autoengaño, es la única perspectiva desde la que podemos dar cuenta de los qualia, de las experiencias personales irrepetibles e incomunicables. Tanto la teoría de la identidad como el funcionalismo pretenden reducir la perspectiva subjetiva a la objetiva, defendiendo que al final la experiencia subjetiva (qualia) puede reducirse a la mostración de sus correspondientes estados cerebrales que en un futuro los científicos nos 
podrán mostrar en la terminal de un ordenador, un autocerebroscopio, como proponía $\mathrm{H}$. Feigle, uno de los defensores de la teoría de la identidad (Feigle, 1967 y Ruiz de la Peña, 1983, pp. 138-144).

Los programas investigadores de la IA, en sentido fuerte, han tenido otros defensores importantes como J. von Neuman, iniciador de la teoría de juegos (Neumann,1958 y Poundstone, 1995-2005), así como N. Wiener, el fundador de la cibernética (Wiener, 1985 y Wiener, 1979), defensor de la vida como entidad anti-entrópica (orientada con una lógica contraria a la ley de la entropía), así como la singularidad de lo humano, aunque defendía también la igualación de lo humano con las máquinas inteligentes en la medida en que, al igual que los funcionalistas, no importa tanto la ontología de las realidades (que son), sino su funcionamiento (actuar como si). Eso lleva a los defensores de la IA en sentido fuerte a igualar a humanos y robots, puesto que si éstos actúan de forma similar a los humanos, es que son iguales a ellos, ya que, según estos teóricos, viene a ser igual que un robot actúe como si supiera chino, que saberlo y entenderlo realmente, no aceptando las críticas de J. Searle al modo de entender la superación de los tests de Turing por los robots (Searle, 2000). Para Searle, los robots inteligentes no poseen la dimensión semántica del lenguaje (no entienden los significados de los signos lingüísticos), ni tampoco la dimensión pragmática (el lenguaje es un instrumento para intercambiar mensajes entre interlocutores) y, en cierta medida, tampoco la dimensión sintáctica (estructura gramatical), porque aunque los robots son máquinas construidas con una determinada estructura informática para realizar unas funciones programadas, ellos no son conscientes de esa sistematización. Para que se posea la conciencia de la dimensión sintáctica se necesita estar dotado de una mente como la humana. Las máquinas, por muy inteligentes que sean, siempre serán artefactos construidos para realizar unas funciones determinadas, incluso cuando estén construidos con altas capacidades de recursividad y autocontrol, dos de las características de los seres vivos. Parecen tener, por ello, una orientación teleológica, como los seres vivos (cibernética), pero es una teleología limitada y artificial, siendo capaces de recoger y procesar un cierto grado de información del entorno. Estos reduccionismos están llevando a defender la total igualdad entre hombres y máquinas, y a propugnar una nueva etapa trans-humanista.

Uno de los autores que defienden la futura era robótica y trans-humanista es Hans Moravec (1988 y 1999) en términos muy similares a los que utiliza Ray Kurzweil (2013 y 2012). Ambos autores coinciden en considerar que la aceleración de los logros científicos en el 
área de la ingeniería informática y la IA apunta a un momento especial; una Singularidad lo denomina R. Kurzweil, en que la IA de los robots igualará y superará en inteligencia a los humanos. Para Moravec, tal situación se podría dar hacia el 2050, mientras que para Kurzweil se adelantará al 2045. Estaríamos, por tanto, ante un salto cualitativo en el proceso evolutivo, en el que se produciría un paso progresivo desde el homosapiens a la machina sapiens (Tajadura, en Carbonell y Flamarique, S. F. pp. 255-271). Este tipo de construcciones robóticas ha recibido diferentes nombres como cyborg, ${ }^{9}$ robot, ${ }^{10}$ androide/ginoide, ${ }^{11}$ entre otros.

El autor que recientemente se está convirtiendo en referencia del proyecto trans-humanista es Ray Kurzweil (RK), jefe de ingenieros de Google. Hay que decir, de entrada, que el proyecto de RK se sitúa a caballo de las tesis que hemos situado en el ámbito del post-humanismo biónico y las del trans-humanismo robótico. De hecho, tampoco le gusta demasiado el concepto trans-humanismo, en la medida en que su utopía sobre los robots inteligentes y androides/ ginoides no son para él una etapa de superación de lo humano, sino más bien una extensión o ampliación de lo humano a estas máquinas artificiales. Los objetivos de RK se encaminan a utilizar todas las aportaciones de las biotecnologías y tecnologías informáticas (tecnolo- gías convergentes) en la mejora de lo humano. Como defensor de la IA en sentido fuerte, está convencido de que los robots del futuro podrán llegar a ser autoconscientes y libres, por lo que no ve razones para no ser consideradas personas, con el mismo reconocimiento a su dignidad que los humanos (Kurzweil, 2012 y Kurzweil, 2013).

Para llegar a esa meta, se tienen que seguir tres etapas: 1) en la primera, se irán implantando prótesis artificiales en el cerebro humano, a través del uso de nanorobots, con lo que conseguiremos potenciar las capacidades intelectuales de los humanos; 2) en una segunda etapa, cuando hayamos conocido en su totalidad cómo están hechos nuestros cerebros, y cómo funcionan, estaremos listos para construir nuevas generaciones de máquinas inteligentes (IA) que igualarán y superarán a la inteligencia humana, de soporte biológico; $3)$ en tercer lugar, se dará la construcción de robots $o$ androides/ginoides tan potentes que tendrán capacidad de reproducirse a sí mismos y construir otros más capaces, pudiendo iniciar de este modo la extraordinaria tarea de colonizar el resto del universo. De este modo, todo el universo parece orientado, piensa RK, hacia el dominio de la inteligencia sobre el conjunto del universo, inteligencia que comienza por hallarse encarnada en la biología para después ser superada por la IA, asentada en silicio o en cualquier otro soporte material. ${ }^{12}$ 
El paso de la segunda a la tercera etapa se producirá, según RK, como hemos dicho, hacia el 2045, momento en el que se dará la anunciada Singularidad, esto es, el momento en que la capacidad de inteligencia de los robots será tal que igualará a la de los humanos, y, a partir de entonces, la superará de forma inevitable. Así que, como indica en uno de sus libros, la singularidad está cerca (Kurzweil, 2012, pp. 25 y 567) será el comienzo de una nueva era, la trans-humanidad. La ingeniería robótica está dando pasos agigantados, siguiendo la ley de los rendimientos acelerados, según la cual, los avances se dan de forma no lineal, sino exponencial. La única dificultad que hay, coincidiendo en esto con otros teóricos, se sitúa en nuestro aún desconocimiento del funcionamiento de nuestro cerebro. Cuando lo conozcamos mejor, a través de implantaciones de nanorobots dentro de él, la ingeniería robótica progresará a velocidades supersónicas sin problemas.

De todas formas, aunque RK defiende sin fisuras la tesis de la IA en sentido fuerte, no defiende las tesis reduccionistas de muchos de sus seguidores. La postura que prevalece entre los defensores de la IA es considerar que la mente humana no es más que un programa de ordenador, por lo que es cuestión de tiempo construir robots inteligentes que pasen sin problemas el test de Turing. En cambio, RK más que reducir la mente humana a la robótica, ya hemos dicho que eleva ésta a la altura de la mente humana, defiende la tesis de un humanismo extendido de lo humano a lo robótico (Monserrat, 2012, pp. 101-118). Por eso, RK considera que estas cuestiones no son exclusivas del ámbito científico, sino que resulta fundamental la mirada filosófica. Esta perspectiva es fundamental, de modo que, frente a muchos teóricos que niegan la existencia de la consciencia y ante la dificultad de objetivarla, RK entiende que es básico aceptar su realidad como característica esencial de los humanos, aunque nos cueste definirla. Por tanto, es en el terreno de la filosofía, no en el de las ciencias, donde se tiene que dirimir esta cuestión. Así, "la cuestión sobre quién o qué es consciente o la naturaleza de las experiencias subjetivas con los otros son temas fundamentales para nuestros conceptos de ética, moralidad y ley" (Kurzweil, 2012, p. 434). La postura de RK, en el ámbito de la filosofía de la mente, se sitúa en un terreno intermedio entre el funcionalismo computacional y un cierto emergentismo consistente en considerar la mente como una propiedad emergente de un sistema físico complejo. Pero esta cercanía al emergentismo la corrige desde un dualismo larvado propio de los funcionalistas, separando y valorando excesivamente la mente (software) frente al soporte cerebral (hardware). Para el paradigma emergentista, en cambio, las características específicas de la mente humana son consecuencia del proceso evolutivo por el que se ha ido conformando el 
cerebro humano, resultado de haber atravesado por las diversas etapas de la historia del cerebro (reptiliano, mamífero y humano). No se entiende la mente al margen del cerebro, puesto que ambos forman una única realidad en la que se conjugan las partes (componentes cerebrales) con la estructura total del cerebro (mente).

RK se acerca un poco a estos planteamientos en la medida en que entiende que lo específico del cerebro humano es el patrón (equivalente a estructura o sistema) con el que se ha ido formando, de ahí que defina su postura como patronismo (patternism): "yo soy principalmente un patrón que perdura en el tiempo. Soy un patrón que evoluciona y puedo influenciar el curso de la evolución de mi propio patrón" (Kurzweil, 2012, p. 442).

La tarea que tiene planteada el trans-humanismo a la hora de construir robots y androides/ginoides con rasgos iguales a los humanos es cómo se podrá realizar esto. Se trata de copiar todos los rasgos específicos de una mente humana en un androide. Pero la cuestión que RK se plantea es si al copiar la mente de una persona humana ese androide será la misma persona o una mera imagen o copia. Al intentar ser copiada toda mi mente en un robot ¿seguiré siendo yo, la misma persona, o un sucedáneo, por muy parecido que sea respecto al original? La cuestión que se halla al fondo de esto, como bien advierte RK, es la esencia de la consciencia, o de la personalidad, del yo. RK se muestra prudente a la hora de responder a esta cuestión, aunque se inclina a pensar que la copia será una persona auténtica. Por el momento, como ya hemos indicado, considera que este tipo de androides o robots tendrán las mismas cualidades que los humanos (autoconsciencia, libertad, responsabilidad, creatividad, entre otras), por lo que podrán ser considerados personas con todos los derechos y obligaciones, sometidos a la normativa ética que habrá que construir para poder establecer las reglas de convivencia entre humanos $y$ androides, y entre los diversos tipos de robots (Kurzweil, 2012, p. 434). Pero la cuestión clave es: ¿quién soy yo? "Esta es, afirma RK, la cuestión ontológica definitiva y normalmente nos referimos a ella como la cuestión de la consciencia" (Kurzweil, 2012, p. 441). Pero tan difícil como la ontología de la conciencia es la correcta comprensión de la libertad. Está claro que la libertad humana está posibilitada por la gran plasticidad cerebral, pero la indeterminación no es sinónimo de libertad. Podemos construir máquinas inteligentes con plasticidad de movimientos, pero eso no garantiza que sean libres. Cuando RK se plantea el tema de la libertad humana, para entender cómo podrá ser el comportamiento robótico, la entiende dentro de la gran indeterminación y complejidad de las leyes del universo, es decir, aunque parece que todo está deter- 
minado, incluso el actuar humano, todo es tan complejo que no puede saberse el futuro, todo está abierto a la indeterminación, lo que sería suficiente, según RK, para que se dé el libre albedrío. RK considera que los humanos poseemos libre albedrío y, aunque no se pueda demostrar, tenemos que actuar como si fuéramos libres (Kurzweil, 2013, p. 227).

Como puede verse, la postura de RK, aunque se halla dentro del panorama del denominado trans-humanismo (y post-humanismo), es capaz de matizar muchas de sus propuestas y poner sordina a sus afirmaciones más fuertes. Por eso, no le convence demasiado ninguno de los dos conceptos, puesto que tienen el peligro de pensar en una época en que los humanos habrán sido no sólo superados, sino también suplantados, por los robots y androides/ ginoides. Más bien, él piensa en una época humana en la que vivirán juntos y suficientemente bien entrelazados, los humanos biológicos con los humanos artificiales, al igual que ocurría en los momentos iniciales de la salida del homo sapiens de África, que tuvo que compartir su existencia con otras especies humanas: los neandertales en Europa y los erectus en Asia. Ahora se trataría de saber convivir con diferentes especies, o metaespecies (Serrano, S. F. pp. 360-363) del género humano: la del homo sapiens (compuestos en su totalidad por biología), la de los hombres biónicos (compuestos en diferente proporción por biología y prótesis metálicas), y la de los robots (humanoides sin biología, sino por piezas de materiales diversos, pero poseedores de personalidad humana extendida). Diversas especies, en definitiva, pero todas ellas supuestamente pertenecientes al mismo género, la humanidad.

Todas estas reflexiones nos llevan a la misma cuestión central: ¿qué es lo humano? ¿Cuáles son las características específicas de la humanidad? ¿Existe algo así como una naturaleza humana? En caso de que respondamos afirmativamente, ¿qué características tendría? $Y$ en caso de que nuestra respuesta fuera negativa, ¿cómo nos posicionamos ante estas importantes cuestiones?

\section{La cuestión del ser o naturaleza de lo humano}

\subsection{Diferentes modos de entender la naturaleza/condición humana}

El concepto de naturaleza humana se ha utilizado con frecuencia en la reflexión antropoló- gica, pero el contenido ha sido muy diverso. Si la pregunta central de la filosofía, desde los griegos, ha sido la pregunta por el ser de una cosa, la misma pregunta se dirigía también hacia los humanos. Su ser o esencia 
era su naturaleza. La dificultad es que atribuir un ser o naturaleza a los humanos, en idéntico sentido que a una cosa, suponía adjudicar a los humanos una estructura esencial de tipo estático, que no permitía desarrollar sus potencialidades, o como mucho suponía situarlo en un carril ya trazado por el que tendría que transcurrir toda su vida.

Sobre todo, a partir del siglo XIX (e incluso a finales del S. XVIII) es cuando el ser humano va tomando consciencia de que el tiempo no es un accidente externo, sino algo intrínseco a su ser y a todo tipo de ser. Esa es la tesis central de los historicistas, de Hegel a Dilthey, que se ha ido completando en los filósofos posteriores como los raciovitalistas (Ortega) y existencialistas. Ese fue un primer atisbo de lo que Heidegger afirmó después claramente: el ser es tiempo, el tiempo es un ingrediente esencial de toda la realidad, y más todavía de los humanos. En el ámbito científico se fue imponiendo también una concepción similar, a partir de la teoría evolucionista darwiniana: la condición abierta y tempórea de la vida, y más aún de la vida humana. Así, las especies no conforman entidades cerradas y bien definidas, sino que son momentos estáticos, miradas momentáneas de un largo proceso evolutivo en el que unos modos de seres (cada especie) van naciendo de otras anteriores, y dan lugar a otras posteriores que continúan el proceso evolutivo. De ahí que con el evolu- cionismo, el concepto de especie se relativiza y pierda el toque esencialista que poseía en una concepción estática de lo biológico, cuyo último representante lo constituyó el naturalista Linneo.

En definitiva, se impone de forma generalizada el hecho de que el ser humano no tiene naturaleza, sino que tiene historia, en expresión gráfica de Ortega y Gasset. Tanto los historicismos como los existencialismos insistirán en que lo que nos diferencia de las demás especies animales es que nuestra esencia no ha quedado marcada ni por la biología ni por ninguna fuerza divina que nos señale el camino de nuestra realización, sino que nuestro ser depende de lo que nos propongamos libremente ser. Nuestro ser y nuestra naturaleza se convierten, de este modo, en una tarea abierta. El ser humano, dice también Ortega, está abierto en un doble sentido: tiene que hacerse y al mismo tiempo tiene que decidir en qué dirección tiene que hacerse. No es un factum, sino un faciendum. Más radical será Sartre que insiste en la libertad absoluta de los humanos, por lo que la existencia precede a la esencia. De este modo, si queremos hablar de esencia en el existencialismo, nos tendremos que referir sólo al conjunto de decisiones y de momentos existenciales que dejamos detrás de nosotros, como la estela de un avión, pero esa esencia es el pasado, no nos condiciona ni nos determina, no hay nada que influya 
en nuestras decisiones en el empeño de realizarnos y conformar nuestra vida. De ahí que, para los existencialistas, más que hablar de naturaleza hay que hablar de condición humana.

\section{2 ¿Una vuelta a la naturaleza humana $y$, al mismo tiempo, a una concepción de lo humano como absoluta plasticidad?}

Con el avance del biologismo materialista y reduccionista se está volviendo a reivindicar la idea de naturaleza humana, pero se trata tanto de una recuperación ontológica sino naturalista de esa naturaleza. Los avances de la genética, de las neurociencias, la etología y demás ciencias del comportamiento animal y humano están dejando obsoletas las filosofías antropológicas que tienden a concebir lo humano como una realidad totalmente libre $\mathrm{y}$ plástica, independiente tanto de los condicionantes biológicos (genética y cerebro) como sociales.

Es evidente que no sólo nuestro fenotipo morfológico, lo mismo que en el caso de los demás animales, depende de la expresión de nuestro genoma. Aunque es evidente que tal expresión se nos está mostrando cada vez más compleja, como nos lo hacen ver la epigenética, la biología del desarrollo y las distintas investigaciones sobre la relación entre genoma y cerebro. Pero esta relación entre la estructura genómica y cerebral y su correspondiente expre- sión fenotípica no se reduce al ámbito morfológico sino también al conductual y comportamental. Para ciertas teorías biologistas, como la sociobiología, la psicología evolucionista y otras, la conducta humana estaría en gran parte conformada y articulada por nuestros genes, que seguirían ya sea la estrategia del egoísmo genético o los parámetros psicológicos conformados por el esfuerzo de sobrevivir a lo largo de nuestra dilatada historia de cazadores-recolectores. Críticos rotundos de la idea de plasticidad absoluta de lo humano, representada por quienes entienden la psique humana como una tabla rasa, tienen planteamientos que se mueven en un terreno ambiguo como para poder escapar a quienes les consideran deterministas, explícitos o encubiertos.

Es cierto que resultan exageradas las teorías que entienden lo humano como una absoluta plasticidad, pero no es menor exageración defender lo humano como una expresión rígida (más o menos controlada) de sus genes, negando la libertad y reduciendo la diversidad cultural e individual de nuestros comportamientos a pura ley de probabilidades o a meras diferencias provocadas por las circunstancias ambientales y ecológicas de cada cultura. Frente a estos planteamientos extremos, es evidente que la mayoría de los estudiosos se decantan por entender la estructura comportamental del ser humano como una conjunción de aspectos innatos y ambientales, así como el factor inex- 
cusable de las decisiones de cada individuo, decisiones que gozan de una cierta y suficiente libertad, es verdad que situada y recortada, pero no absoluta. Ahora bien, a la hora de analizar tanto el ingrediente innato como el ambiental de nuestra fórmula comportamental, resulta difícil situarse en el virtuoso término medio. Suele ocurrir más bien que las diferentes teorías tienden a decantarse por acentuar uno de los dos extremos, sea el innatismo o la influencia del entorno ambiental y cultural, con lo que se vuelve a reproducir el viejo debate, aunque de otra manera.

De todas formas, en relación con el tema de las propuestas post/ trans-humanistas que motivan estas reflexiones y su forma de entender la naturaleza humana, resultan quizá tan o más determinantes y preocupantes las posturas que se decantan por negar o relativizar la idea de naturaleza humana, entendiendo lo humano como una realidad totalmente plástica y, por tanto, susceptible de cualquier tipo de mejoras ilimitadas, elegibles por cada individuo, sin que se vea en ello la necesidad ni la legitimidad ética de apelar a una naturaleza humana que nos marque determinadas líneas rojas que impidan utilizar determinados avances tecnológicos a la mejora de lo humano. Es la línea que defienden algunos post/trans-humanistas que tienden a no ver diferencias entre la aplicación y uso de estas biotecnologías o antropotecnias de forma terapéutica o de mejoramiento de lo humano, e incluso con fines eugenésicos. Es más, algunos consideran no sólo legítimas estas praxis, sino incluso obligatorias moralmente. En caso de que no haya criterios éticos claros, tienen claro que nadie tiene que interponerse a la hora del uso libre de tales antropotecnias para la mejora de ellos mismos o de sus descendientes. El ser humano es una realidad totalmente plástica y el ámbito de decisiones para las mejoras y supuestos perfeccionamientos de lo humano se tiene que dirigir, según ellos, desde la omnímoda libertad de decisiones de cada individuo.

La relación entre la idea de naturaleza humana y lo que hemos denominado trans-humanismo robótico se contempla de diferente forma. Necesitamos también apelar a una idea de naturaleza humana y dilucidar qué entendemos por ello cuando analizamos y discutimos las pretensiones de los trans-humanistas robóticos de construir robots inteligentes (androides/ginoides) que poseerían, según estos autores, una naturaleza humana extendida, en la medida en que serían exactamente iguales a los humanos, con idénticas características a nosotros, esto es, autoconscientes, capaces de experimentar emociones, dotados de pensamiento abstracto y simbólico, así como libres y responsables y con demás capacidades consideradas como humanas. Para ellos está claro que si llegan a poseer estas cualidades no tendrá sentido ni habrá 
excusas para negarles la condición de personas, tratándolos con los mismos cuidados y otorgándoles la misma dignidad que atribuimos a las personas humanas. El problema es que este planteamiento implica, entre otras cosas, la impresión que se apoya en una concepción dualista de lo humano, en la que lo corpóreo es minusvalorado para situar el núcleo de la persona en lo mental, entendido además como un programa complejo computacional que puede copiarse y manipularse a nuestro antojo. La crítica es que, desde la filosofía de la mente, este funcionalismo computacional recibe de posturas como el emergentismo sistémico o el estructurismo dinámico, se orienta tanto a poner en cuestión su dualismo larvado como a entender que el peso de la prueba se sitúa en el tejado de este transhumanismo robótico.

Es decir, la concepción del funcionalismo informático de entender la relación entre mente y cerebro de forma similar a la que hay en una computadora, entre el software y el hardware, supone dar por hecho que lo central es el programa (software) siendo indiferente el soporte material (hardware), que puede ser de silicio o de cualquier otro material. En cambio, el emergentismo sistémico considera que el ser humano es una estructura unitaria psico-orgánica en la que lo mental se entiende como la estructura dinámica de lo corpóreo. Por tanto, el cerebro biológico sí que importa, de tal manera que lo mental humano, con las características propias de los humanos, es el resultado de un largo proceso evolutivo de nuestro cuerpo y el cerebro es un órgano fundamental en el que se apoya lo mental, a través del cual la estructura cerebral ha ido pasando de un cerebro/mente repitiliano a otro mamífero, hasta llegar al cerebro/ mente humano. Así, nuestra mente es como es en virtud de la estructura de este tipo de cerebro que se ha ido conformando en un diálogo con el entorno ecológico e interhumano. De ahí que pensemos que sólo los humanos somos personas y poseemos la dimensión ética que nos convierte en sujetos morales y poseedores de una dignidad que hay que respetar.

Los robots, por más perfectos que se quieran imaginar, siempre serán construcciones humanas. De ahí que atribuirles personalidad, así como dignidad ética, es una pretensión exagerada y poco convincente. En definitiva, y en último término, el peso de la prueba está situado en su propio tejado.

\subsection{La naturaleza humana como estructura bio-psico-cultural}

Frente a estas propuestas
extremas sobre la naturaleza
humana, su naturalización y su
extensión o copia informática que-
remos defender una idea de la
naturaleza humana como estructura
bio-psico-cultural abierta. Enten-


demos que no resulta acertado definir lo humano como una esencia o naturaleza cerrada y estática en la línea esencialista de la ontología greco-medieval, pero tampoco nos parece adecuada la sustitución del esencialismo apelando a un concepto tan amplio y difuso como la condición humana, entendida como una realidad totalmente plástica, para insistir de ese modo y poner a salvo la dimensión abierta y libre de nuestra realidad.

Las aportaciones de todas las ciencias de lo humano nos están poniendo en evidencia que lo humano es el resultado del proceso evolutivo (componente bio), por lo que un componente básico de nuestra realidad es la referencia a nuestro genoma. Pero se trata de un genoma que, como resultado de ese mismo proceso evolutivo, ha superado la rigidez expresiva de las especies animales elementales para dar de sí y hacer emerger una nueva estructura o fórmula vital que se halla dotada de conciencia, pensamiento simbólico, libertad y demás cualidades específicas de lo humano. Esta nueva fórmula o estructura vital, emergida en el proceso evolutivo, es lo que denominamos mente (componente psico), una mente que no se reduce ni a mera expresión conductual ni al conjunto de estados cerebrales, ni tampoco a la expresión funcional de diversos programas informáticos, como defiende el funcionalismo y la IA fuerte. La mente es la estructura específica del cerebro humano que actúa como un todo, no como mera suma de sus componentes neuronales, por lo que no se reduce ni a estados cerebrales ni podrá ser imitada, copiada o extendida a mecanismos robóticos. Para completar esta visión, se sostiene que esto es así porque los humanos no somos personas al margen del entorno interpersonal y social. Un individuo humano, por más normal que sea en lo genético y mental, si no ha contado en el itinerario de su maduración como persona con un entorno social maduro y humanizador será siempre una persona fallida. Le faltarán los diversos mecanismos y procesos de educación y socialización que nos permiten madurar como personas y entablar una relación normal con los demás humanos. Ello supondrá que incluso no habrá aprendido a hablar, ni poseerá un pensamiento simbólico y abstracto; no será capaz de enriquecer su mente con el conjunto de ingredientes que adquirimos por herencia cultural, ni siquiera será capaz de poseer una personalidad y autoconciencia similar a la nuestra, en la medida en que la conformación y maduración de la persona (del yo) constituye un proceso que se consolida y realiza en una relación dialéctica con los otros. No hay un yo sin un tú, sin los otros humanos, con los que conformamos un nosotros humanizador.

Los intentos de recuperar la naturaleza humana para reducirla a la estructura genómica, o bien extender esta naturaleza a máquinas robóticas, adolecen de alguno de estos tres elementos que hemos visto 
que componen la realidad de los humanos. Los biologistas reducen lo mental a lo biológico-cerebral, y olvidan totalmente la dimensión social. Los defensores de la IA fuerte reducen lo mental a programas informáticos, todo lo complejo y sofisticado que se quiera, olvidando su base biológico-genética y también su dimensión social. Por más sofisticado que se quiera entender la capacidad mental de los androides del futuro, no tenemos que confundir actuar como si parecieran humanos que serlo realmente. Para ello necesitarían de los largos procesos biológicos y sociales en los que los humanos nos vamos conformando y madurando.

No se trata de temer la recuperación del concepto de naturaleza humana, como el título de algún libro parece sugerirlo (Castro Nogueira, 2016), sino las incorrectas interpretaciones de la misma, bien sea por entenderla de un modo reductivo (lo genético), o bien desde una plasticidad tan exagerada que suponga disolverla. La complejidad de lo humano, que nos hace descubrirnos ante nosotros mismos como realidades problemáticas, no fácilmente asequibles y definibles (de ahí la afirmación de Pascal: "el hombre sobrepasa infinitamente al hombre"), nos hace demorarnos y andar con cuidado a la hora de definirnos de forma demasiado rápida y simplona. Una correcta definición de lo humano tiene que comprender los elementos con los que la naturaleza nos ha dotado, así como la dimensión abierta en lo individual y social. De este modo, nos movemos en un ámbito intermedio entre la rigidez de los que defienden una naturaleza cerrada y los que hablan de condición humana, para dar entrada y concernir nuestra dimensión de plasticidad y libertad. Por eso apelamos a la definición de lo humano como una estructura bio-psico-social abierta.

Hemos de ser conscientes, para terminar, que se trata de una definición formal y provisional. Formal, por cuanto es una mera descripción de los componentes básicos de nuestra realidad, componentes sobre los que sabemos poco, por lo que las ciencias que se encargan de investigarlos nos obligan permanentemente a enriquecer constantemente la visión de lo humano. Por ello, es una fórmula provisional, obligada a rellenar de forma permanente los contenidos de dicha fórmula. Lo humano está en permanente proceso de realización, de autorrealización, teniendo que navegar entre Escila (naturalismo) y Caribdis (plasticidad absoluta), condición que hace difícil discernir y posicionarse de forma definitiva y contundente ante las pretensiones de los post-humanismos y trans-humanismos de los que hemos hablado.

\subsection{Descubrir y construir los límites de nuestra estructura esencial}

Como hemos visto al referirnos a los diversos post/trans-humanismos, 
hay quienes, desde una idea totalmente plástica de lo humano, apelan a una eugenesia totalmente liberal, dejada en manos de las decisiones individuales arbitrarias, y libre de cualquier limitación y prohibición social. En ello coinciden con la idea de condición humana defendida por las corrientes existencialistas europeas de mitad del siglo XX. Pero, frente a este modo de entender la realidad humana como totalmente plástica, nos parece más correcta la postura de Habermas y de otros pensadores que entienden lo humano entre la plasticidad/apertura y una serie de límites que no podemos sobrepasar si no queremos destruir lo humano. Esos límites de lo humano no se sitúan tanto en el terreno de lo biológico, sino ante todo en el ámbito de lo cultural y ético. Esto es, los límites que no hay que traspasar son la dignidad humana, la igualdad de todos los seres humanos, la condición social y responsable con los otros, sobre todo con los más débiles.

Ahora bien, estos límites no están dados de una vez por todas, sino que los vamos descubriendo y construyendo de forma dinámica y en diálogos interpersonales que nos llevan a consensos racionales, como consecuencia de la puesta en práctica de nuestra condición racional, de nuestra racionalidad comunicativa.

De ahí que esta postura, basada en este modelo de ser humano, no esté de acuerdo con las tesis del individualismo a ultranza defendido por la eugenesia liberal, puesto que resulta contradictorio apelar a la mera y absoluta decisión y responsabilidad individual en cuestiones y decisiones que tienen tan graves consecuencias no sólo para los individuos que las toman, o sus parientes más cercanos, sino para todos los seres humanos. Eso es lo que nos hace ver que los humanos no somos mónadas aisladas, sino realidades que estamos entrelazadas con los demás congéneres desde antes incluso de que nazcamos. Ya desde nuestra dimensión biológica estamos vertidos a los demás, y no podemos realizarnos sin ellos y al margen de ellos.

En este proceso interminable de ir definiendo y construyendo lo humano es donde se sitúa el esfuerzo por construir nuestra humanidad, tanto en la dimensión individual como social. Es ahí, con este procedimiento de reflexión comunitaria donde y como tenemos que dilucidar lo adecuado o no de las diversas propuestas de mejoramiento de lo humano. Por tanto, en este ámbito de reflexión hemos de avanzar distinguiendo y conjugando dos niveles de la realidad antropológica que son similares en el campo de la ética: los universales antropológicos (similar a lo que en el terreno de la ética se denomina la ética de mínimos, ética del deber) (Cortina, 1986) y la pluralidad de modelos particulares de lo humano (equivalente a la ética de 
máximos, del bien o de la felicidad), aspectos que quedan más a la decisión de cada cultura o individuo. Es fundamental saber conjugar y complementar ambas perspectivas, porque no todos coincidimos en los contenidos de un modelo ideal de lo humano, pero sí podemos intentar coincidir en unos universales antropológicos, esto es, en los requisitos mínimos o en los límites necesarios que no habría que traspasar o transgredir para respetar al otro, para no herir o destruir lo auténticamente humano.

Estos universales antropológicos o mínimos humanos representarían el fundamento y apoyo teórico de la ética de mínimos y la base de los derechos humanos básicos. Ahora bien, la cuestión es cómo se llega a tales resultados consensuados. En principio, no parece que sea fácil llegar a contenidos materiales que conformen esos universales antropológicos o mínimos humanos, sino que sólo podemos apuntar a procedimientos formales, al estilo del propuesto por la racionalidad comunicativa de Habermas y Apel.

\subsection{Ahondando en este proceso o procedimiento racionalizador}

A pesar de la plausibilidad de esta propuesta de la racionalidad comunicativa, hay quienes la consideran insuficiente, proponiendo completar esos requisitos formales de la racionalidad comunicativa y la ética del discurso con otra serie de principios básicos. Es la propuesta que hace $\mathrm{E}$. Dussel, en su Ética de la liberación (Dussel, 1998), donde propone una fundamentación de la ética no sólo en un principio, sino en un conjunto de ellos (una arquitectónica), propuesta más ambiciosa que la ética del discurso y que otras propuestas similares que son mono-principiales (basadas en un único principio). Dussel, en concreto, propone conjugar tres principios básicos: el principio material, que tendría como imperativo básico la defensa de toda vida humana, de toda vida humana en comunidad; el principio formal, que nos indica el procedimiento racional para decidir de forma consensuada qué entendemos por vida humana y cómo tenemos que defenderla en sociedad; de este modo, sólo consideraremos decisiones y criterios éticos legítimos cuando se decidan en un consenso racional, en el que hayan participado todos los implicados; yel principio de factibilidad, que nos manda atenernos a la realidad ya los recursos con que se cuenta, pues nadie está obligado a realizar lo que no puede hacer, lo que no es factible. Para dilucidar qué es factible o no, hay que echar mano de la racionalidad instrumental.

Ahora bien, a pesar de poner en práctica estos tres principios, nunca podremos asegurar que lleguemos a construir una sociedad e instituciones perfectas. Por ello, incluso la sociedad que se pretenda construir 
con estos principios será imperfecta y producirá víctimas. Eso nos lleva a la necesidad de reformular esos tres principios desde la mirada de las víctimas, desde los perdedores de la sociedad y de la historia. Estas propuestas sobre la estructura esencial de lo humano, así como de los principios esenciales de la ética, no se contradicen con una visión creyente del ser humano y de la realidad. Es un error pensar que la visión del Dios creador suponga una naturaleza humana, consecuencia de su labor creadora, por lo que parecería que la visión cristiana tendría que defender necesariamente la postura que se suele llamar iusnaturalista.

En primer lugar, ya hemos dicho que la naturaleza y la realidad humana en general se nos presenta como una realidad o naturaleza abierta, no sometida ni a leyes biológicas ni sociales cerradas ni rígidas, sino atenidas a la evolución y a maduración, cuyas concreciones dependen de la racionalidad humana. Lo específico de lo humano no es la biología, sino la racionalidad. La voluntad de Dios tiene que consistir en que el ser humano use la razón de la forma más transparente y profunda, y eso es lo que pretende la propuesta de la racionalidad comunicativa, con las correcciones que hemos presentado desde Dussel.

"La gloria de Dios es que el hombre/mujer viva", afirmaba $\mathrm{S}$.
Justino ya a finales del siglo II, y Mons. Romero transformaba y completaba diciendo: "la gloria de Dios es que los pobres vivan". Y la forma de conseguir este objetivo es reflexionando entre todos los humanos sobre los medios más adecuados para hacer una sociedad en que eso sea posible, esto es, una sociedad en que todos los hombres sean reconocidos con igual dignidad y respeto, y que todos los humanos tengan los recursos necesarios para vivir con dignidad (comida, vivienda, trabajo, educación, ocio digno, entre otros). Y este objetivo no debe imponérsenos de forma paternalista (despotismo ilustrado), sino que hay que tratar de conseguirlo entre todos (democracia participativa, el principio formal), repartiendo por igual entre todos los recursos naturales que tenemos, que son de todos. Esta es la voluntad de Dios, quien nos ha creado y nos ha dotado de la base biológica y la inteligencia suficiente para ello. No es ir contra Dios cuando se va contra supuestas leyes naturales, porque lo natural dentro de lo humano, ya lo hemos dicho, son las diversas leyes históricas y culturales, que van continuamente cambiando y acomodándose a las nuevas necesidades humanas.

\section{Concluyendo}

El ser humano es fruto de la evolución y no puede ser entendido al margen de ella. Pero no se reduce a ella, sino que tiene capacidad para conocer sus leyes y superarlas. Ahí reside precisamente su singularidad, 
siendo el único animal bio-cultural, fruto dos herencias: la biológica y la cultural. Así se ha experimentado a lo largo de la historia y más en la actualidad en la que sus capacidades tecnológicas están alcanzando unos niveles nunca vistos y con una capacidad de impacto en el entorno ecológico y en la propia realidad humana que nos obligan necesariamente a reflexionar en serio sobre sus peligrosas consecuencias.

La extraordinaria capacidad de las biotecnologías y las antropotecnias están originando que ciertos estudiosos nos hablen de la cercanía de una época en que se llegará a superar lo humano, para adentrarnos en una época post/trans-humana. Ya hemos visto que las propuestas utópicas sobre esa supuesta época futura son muy variadas y dispares, distinguiéndose entre las que se sitúan en el ámbito terapéutico y las que pretenden llegar a lo eugenésico. Las propuestas terapéuticas son más fáciles de aceptar y de alcanzar consensos éticos racionales sobre ellas. No es tan fácil alcanzar esos consensos en relación a ciertas propuestas utópicas, como la búsqueda de la inmortalidad, los intentos de practicar la clonación con humanos y, sobre todo, la intervención en la estructura germinal humana.

En todos estos casos nos encontramos ante la necesidad de interrogarnos por el ser o la naturaleza humana, advirtiendo que la decisión más razonable es situarnos en una postura intermedia entre una idea rígida y cerrada de naturaleza y la que defiende una condición humana totalmente abierta y plástica. Más bien, proponemos para definir lo humano una estructura bio-psico-social abierta, que respetando la estructura germinal humana y su correspondiente conformación cerebralmental, se esfuerce en delimitar y respetar los límites antropológicos y éticos que los humanos vayamos alcanzando en un esfuerzo consensuador, como resultado de la puesta en práctica de la racionalidad comunicativa y la ética del diálogo. Ese principio formal tiene que ser completado por el principio material anclado en la defensa de toda vida humana, así como respetando el principio de factibilidad, siempre desde la mirada de las víctimas y de los perdedores de la historia.

Estos principios antropológicos y éticos sólo funcionan si los humanos creemos en ellos y los queremos poner en práctica, en caso contrario, es muy posible que queden estériles. El mayor enemigo de estos esfuerzos consensuadores es el cinismo, la razón cínica, esto es, la actitud del que sabe qué es lo correcto, humano y ético, pero no le interesa perseguirlo, porque considera que va en contra de sus intereses. $Y$ ese es el dilema en el que parece que nos encontramos los humanos en la actualidad, aunque también ha sucedido siempre. Por un lado, vivimos en una sociedad con grandes logros en el ámbito de la racionalidad instrumental, que puede producir 
alimentos para todos, medicinas para curar casi todas las enfermedades, colegios y universidades para que todos se formen, casas para que todos puedan vivir dignamente, carros, trenes, aviones y demás medios para que todos podamos viajar sin problemas, medios de comunicación (periódicos, TV, radios, internet, redes sociales, entre otros) para que todos podamos enterarnos de la realidad, procedimientos democráticos para que todos podamos participar en la elección de nuestros representantes políticos, entre otros, pero por intereses particularistas y egoístas de unos pocos, muchos millones de humanos no llegan a disfrutar de todo esto en su justa medida.

En definitiva, se da una enorme disparidad y distancia entre los esfuerzos que ponemos en utilizar la racionalidad instrumental: construir productos de consumo, que persiguen mejorar aspectos accidentales y segundarios de lo humano, y una racionalidad integradora (antropológica y ética crítica) que se pregunte si todos esos logros son suficientes para darnos la felicidad, y una felicidad para todos. Porque lo que no es universalizable no es humano y, por tanto, no puede ser ético. Así, las tecnologías siguen avanzando, al parecer sin preocuparse demasiado por las consecuencias negativas que puedan acarrear a los humanos, sino respondiendo más bien a pulsiones prometeicas (romper barreras, jugar a ser dioses) y economicistas (ganar el mayor dinero posible), dejando por detrás a mucha distancia las reflexiones sociales y éticas que estos problemas llevan implicados.

En definitiva, no acabamos de construir los mecanismos adecuados, en el terreno de la ética y de las decisiones políticas, para que la dinámica científica y tecnológica no nos lleve a situaciones de un sin retorno, como abrir la caja de Pandora de forma que ya no sepamos cerrarla. Es así que se nos muestra en esta situación la extraña condición humana: somos más propicios e inclinados a saber cómo hacer las cosas (racionalidad instrumental y técnica) que a preguntarnos y a reflexionar sobre su utilidad y funcionalidad. Esto es, nos esforzamos más en saber cómo hacer las cosas que cuestionarnos por qué y para qué las hacemos. Nos llenamos de artefactos técnicos, invertimos millones de dinero y de cerebros humanos en ello (la mitad de la inteligencia y de los recursos humanos, según datos investigados, se invierten y se dedican a la industria militar, a la guerra, a matarnos unos a otros), y nos olvidamos de preguntarnos sobre si todo eso nos hace mejores, más felices $\mathrm{y}$, en definitiva, más humanos.

Así, la cuestión que tenemos que platearnos es ¿las nuevas antropotecnias nos van a hacer más humanos, a mejorar nuestra humanidad? Algunas sí, otras muchas no, por lo cual, tendríamos que reflexionar 
y centrarnos en aquellas que nos lado las que no, las que nos pueden humanizan, y limitar y dejar de in-humanizar y destruir.

\section{Referencias bibliográficas}

- Annas, G; Andrews, L. e Isasi, R. (2002). Protecting the endangered human: toward an international treaty prohibiting cloning and inheritable alteration. American Journal of Law and Medicine (28), pp. 151-178.

- Ayala, F. J. (2015). ¿De dónde vengo? S. E.

- _ (S. F.). Origen y evolución del hombre. S. E.

- Ayala, F. J. y Cela Conde, C. J. (2006). La piedra que se volvió palabra. Las claves evolutivas de la humanidad. Madrid, España: Alianza Editorial.

- Ballesteros, J. (S. F.). Biotecnología, biolítica y posthumanismo. En J. Ballesteros, E. y Fernández (Coords.), Biotecnología y post-humanismo. (S. E.)

- Beorlegui, C. (2001). ¿Hacia un humanismo trans-antropocéntrico? Peter Singer y los "derechos" de los animales. Realidad (80), pp. 199-236.

- (2009). Antropología filosófica. Nosotros: urdimbre solidaria y responsable. Bilbao, España: Universidad de Deusto.

- . (2015). El post-humanismo robótico de Ray Kurzweil. Un análisis crítico. Estudios Filosóficos LXIV (187), pp. 439-472.

- $\quad$ (2016). Antropología filosófica. Dimensiones de la realidad humana. Madrid/Bilbao, España: UPCO/Universidad de Deusto.

- Bostrom, N. (2005). The Fable of the Dragon-Tyrant. Journal of Medical Ethics, Vol. 31 (5), pp. 273-277.

- Castro Nogueira, L; Castro Nogueira L. y Castro Nogueira M. A. (2016). ¿Quién teme a la naturaleza humana? Madrid, España: Tecnos.

- Copeland, B. J. (2013). Alan Turing. El pionero de la era de la información. Madrid, España: Turner.

- Cortina,A. (1986). Ética mínima. Introducción a la filosofía práctica, Madrid, España: Tecnos.

- $\quad$ (1993). Un concepto "transformado" de persona para la bioética. En A. Cortina, Ética aplicada y democracia radical (pp. 223-240). Madrid, España: Tecnos.

- De Waal, F. (2016). ¿Tenemos suficiente inteligencia para entender la inteligencia de los humanos? Barcelona, España: Tusquets.

- Diéguez, A. (2017). Transhumanismo. La búsqueda tecnológica del mejoramiento humano. Barcelona, España: Herder.

- Dussel, E. (1998). Ética de la liberación en la época de la globalización y de la exclusión. Madrid, España: Trotta.

- Engelhardt, H. T. (1995). Los fundamentos de la bioética. Barcelona, España: Paidós.

- Feigle, H. (1967). The "Mental" and the "Physical". Minneapolis, USA.

- Feito Grande, L. (2011). La búsqueda de la perfección: ¿realización de lo humano o pacto con el diablo? En J. San Martín y T. Domingo Moratalla (Eds.), Perspectivas sobre la vida humana. Cuerpo, mente, género y persona (pp. 214-236, 219). Madrid, España: Biblioteca Nueva. 
- Ferry, L. (2017). La revolución transhumanista. Cómo la tecnomedicina y la uberización del mundo van a transformar nuestras vidas. Madrid, España: Alianza editorial.

- Fukuyama, F. (2002). El fin del hombre. Consecuencias de la revolución biotecnológica. Barcelona, España: Ediciones B. . (Noviembre de 2004). Transhumanism. Foreing Policy. S. E.

- Gardner, H. (1987). La nueva ciencia de la mente. Historia de la revolución cognitiva. Barcelona, España: Paidós.

- Giesbert, F. O. (2016). Un animal es una persona. Para los animales, hermanos nuestros. Barcelona, España: Alfaguara.

- Habermas,J. (2002). El futuro de la naturaleza humana. ¿Hacia una eugenesia liberal? Barcelona, España: Paidós.

- Harris, J. (1998). Supermán y la mujer maravillosa. Madrid, España: Tecnos.

- Huxley, J. (1957). In New Bottles for New Wine. Londres, Inglaterra: Chatto and Windus.

- Jonas, H. (1994). El principio responsabilidad. Barcelona, España: Herder.

- Kass, L. (1997). The wisdom of repugnance. The New Republic. S. E.

- Kurzweil, R. (2012). La singularidad está cerca. Cuando los humanos trascendemos la biología. Berlín, Alemania: Lola Books GbR.

- . (2013). Cómo crear una mente. El secreto del pensamiento humano. Berlín, Alemania: Lola Books.

- Lewontin, R. (1984). La diversidad humana. Barcelona, España: Editorial Labor.

- _ (2001). El sueño del genoma humano y otras ilusiones. Barcelona, España: Paidós.

Marcos, A. (2016). La mejora (de la vida) humana: una reflexión antropológica y ética. En J. Torre, (Ed.), Cultura de la mejora humana y vida cotidiana (p. 18, 15-29). Madrid, España: UPCO.

- . (Noviembre de 2010). Filosofía de la naturaleza humana. Eikasía. Revista de Filosofía, año VI (35), pp. 181-208, 192.

- Monserrat, J. (2012). El problema del soporte físico de la sensibilidad-conciencia. En Rodríguez Valls, F. (Ed.), La inteligencia de la naturaleza. Del relojero ciego al ajuste fino del universo. Madrid, España: Biblioteca Nueva.

- Moravec, H. (1988). Mind Children. The Future of Robot and Human Intelligence. Cambridge: Harvard University Press.

- _ _ (1999). Robot: Mere Machine to Trascendent Mind. Oxford University Press.

- Neumann, J. (1958). The Computer and the Brain. New Haven: Yale University Press, (Traducción al castellano: Neumann, J. (1980). El ordenador y el cerebro. Barcelona, España: Bosch).

- Poundstone, W. (1995-2005). El dilema del prisionero. John von Neumann, la teoría de juegos y la bomba. Madrid, España: Alianza Editorial.

- Prieto López, L. (2008). El hombre y el animal. Nuevas fronteras de la Antropología. Madrid, España: BAC.

- Rawls, J. (1975). Teoría de la justicia. México: FCE. (Original de 1971. A Theory of Justice. Cambridge, M. A: Harvard University Press). 
- Rifkin, J. (2009). El siglo de la biotecnología. El comercio genético y el nacimiento de un mundo feliz. Barcelona, España: Paidós.

- _ (1999). El siglo de la biotecnología. Barcelona, España: Editorial Crítica.

- Roco, M. C. y Bainbridge,W. S. (S. F.). “Vista general de las tecnologías convergentes para mejorar el desempeño humano", recuperado de https://ink.springer.com/ chapter/10.1007/978-94-017-0359_1page-1

- Ross Anderson, A. (Ed.) (1984). Controversia sobre mentes y máquinas. Barcelona, España: Tusquets.

- Ruiz de la Peña,J. L. (1983). Las nuevas antropologías. Un reto a la teología. Santander, España: Sal Terrae.

- Sandel, M. (2015). Contra la perfección. La ética en la era de la ingeniería genética. Barcelona, España: Marbot Ediciones.

- Saraceni, G. (S. F.). El cuerpo del delito. Reflexiones jurídico-filosóficas sobre el posthumanismo. En J. Ballesteros y E. Fernández, Biotecnología y posthumanismo. S. E.

- Savagnone, G. (S. F.). Posthumanismo y cine. En J. Ballesteros y E. Fernández, Biotecnología y posthumanismo. S. E.

- Savulescu, J. (2002). Procreative Beneficence: Why We Should Select the Best Children. Bioethics (15-16), pp. 413-426.

- Searle, J. (2000). El misterio de la conciencia. Barcelona, España: Paidós.

- Serrano, J. (S. F.). El hombre biónico. S. E.

- Singer, P. (1999). Liberación animal. Madrid, España: Trotta.

- Skinner, B. F. (1982). Más allá de la libertad y de la dignidad. Barcelona, España: Fontanella.

- Tajadura, B. S. (S. F.). Posthumanismo y machina sapiens. La destrucción del sujeto a través de Foucault, Deleuze y Derrida. En C. L. Carbonell y L. Flamarique (Eds.), De simios, cyborgs y dioses. La naturalización del hombre a debate. S. E.

- Tartaglia, G. G y Cirillo, D. (2016). Biotecnología. La vida al servicio de la vida. Barcelona, España: Batiscafo, S. L.

- Toffler, A. (1973). El "shock" del futuro. Barcelona: Plaza y Janés.

- Torralba Roselló, F. (2005). ¿Qué es la dignidad humana? Ensayo sobre Peter Singer, Hugo Tristram Engelhardt y John Harris. Barcelona, España: Herder.

- Turing, A. M; Putnam, H. y Davidson, D. (1985). Mentes y máquinas. Madrid, España: Tecnos.

- Ursúa, A. (2010). ¿Tendrá la “Convergencia de Tecnologías” (CT) y la “Mejora Técnica del Ser humano" un impacto similar al darwinismo? Implicaciones y consideraciones filosóficas". Endoxa (24), pp. 311-329.

- Wiener, N. (1979). Cibernética y sociedad. Buenos Aires, Argentina: Editorial Sudamericana.

- (1985). Cibernética. El control y comunicación en animales y máquinas. Barcelona, España: Tusquets. 


\section{Notas}

1 Para un primer acercamiento, Cfr. Ferry (2017) y Diéguez (2017).

2 Cuando se habla en la actualidad de las nuevas teconologías (NBIC), se está haciendo referencia a la convergencia de las innovaciones tecnológicas aplicadas a lo humano en los terrenos de la Nanotecnología, Biotecnología, Informática tecnológica (big data) y Ciencias Cognitivas (IA fuerte). A estas tecnologías hay que añadir, como indica Ferry (2017),"La robótica, las impresoras 3D, las terapias reparadoras con ayudas de células madre, así como las diferentes formas de hibridación hombre/ máquina” (p. 189); “Anexo. Para comprender los NBIC", (Ferry, 2017, pp. 189-208). También Roco, M.C./Bainbridge,W. S. "Vista general de las tecnologías convergentes para mejorar el desempeño humano", recuperado de https:// link.springer.com/chapter/10.1007/97894-017-0359_1page-1; (Kurzweil, 2012); (Ursúa, 2010, pp. 311-329).

3 Cfr. Ferry (2017, p. 11).

4 Cfr. Ayala y Cela Conde (2006); Ayala (S. F. Cap VIII); Ayala (2015, p. 12) y Tartaglia y Cirillo (2016).

5 Cfr. Singer (1999); Engelhardt (1995); Harris (1998); Beorlegui (2001, pp. 199-236) y Torralba Roselló (2005).

6 Algunos autores se atreven, aunque sin preocuparse en argumentarlo, a denominar personas a los animales (Giesbert, 2016).

7 Cfr. Huxley (1957, pp. 13-17). Ese mismo año de 1957, Huxley publicó Towards a New Humanism (Hacia un nuevo humanismo); Feito Grande (2011, pp. 214-236 y 219).

8 Es el argumento que utiliza otro bioconservador, Rifkin en El siglo de la biotecnología (1999).

9 El término cyborg aparece alrededor de los años 50 del siglo pasado, acuñado por Manfred Clynes y Nathan Klynes, y fue popularizado sobre todo por las novelas de ciencia ficción de I. Asimov. Se entiende un cyborg como una criatura que posee una parte humana, el cerebro, mientras que el resto estaría compuesto por diferentes piezas o prótesis de tecnología, que es pensada en un primer momento como un organismo humano capaz de sobrevivir en medios extraterrestres, por eso se trataría más bien de una figura a situar, como ya lo vimos en su momento, dentro de las propuestas del post-humanismo biónico (Saraceni, S. F. pp. 139-152 y 139).

$10 \mathrm{El}$ concepto de robot, como indica J. Ballesteros, se encuentra por primera vez en la obra de teatro del dramaturgo checo $\mathrm{C}$. Capek, titulada R. U. R. (traducción en Alianza Editorial), y se utiliza representando a un esclavo mecánico, que no necesariamente tiene la figura de un humano. La diferencia entre un cyborg y un robot es la misma que hay entre Terminator (robot) y Robocop (cyborg) en los filmes que tratan de estos temas (Ballesteros, S. F. p. 29, nota 19).

11 Los androides o ginoides hacen referencia a robots construidos imitando la morfología corpórea de los humanos así como su inteligencia. Tienen la pretensión de igualar y superar al ser humano tanto en capacidades intelectuales como también en belleza corpórea, aunque carecerían de sentimientos, excepto toscas reacciones ante los otros, programadas como parte de su comportamiento. Un buen ejemplo de ello serían los androides de la serie televisiva norteamericana Humans. En realidad, podríamos decir que la propuesta del trans-humanismo se orienta a la construcción de androides que fueran lo más parecidos, en todos los aspectos, a los seres humanos (Savagnone, S. F. Cap. IX, pp. 189-214).

12 No vamos a detenernos a exponer el conjunto de las propuestas de RK. Para esa visión conjunta, Cfr. Beorlegui (2015, №. 187, pp. 439-472). 